\title{
ظاهرة المرأة المعيلة والآثار المترتبة عليها دراسة ميدانية بححافظة البحيرة
}

\author{
أعـداد \\ أ. شيماء أحمد محمد صالح \\ باحثة ماجستير - قسم الاجتماع \\ كلية الآداب - جامعة دمنهور
}

مجلة الدراسات التربوية والانسانية ـ كلية التربية ـ جامعة دمنهور

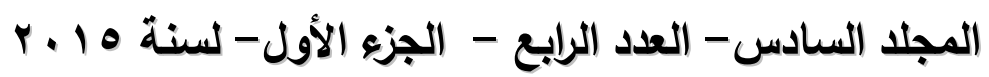


ظاهرة المرأة المعيلة والآثار المترتبة عليها "دراسة ميدانية" بمحافظة البحيرة أ. شيماء أحمد صالح 


\section{ظاهرة المرأة المعيلة والآثار المترتبة عليها}

\section{دراسة ميدانية بمحافظة البحيرة}

أ.شيما أحمد محمد صالح

مقدمة الدراسة:

تعتبر ظاهرة المرأة المعيلة من الظواهر الاجتماعية الهامة التي أخذت في

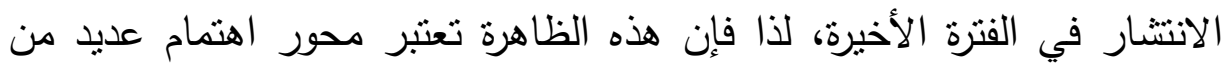

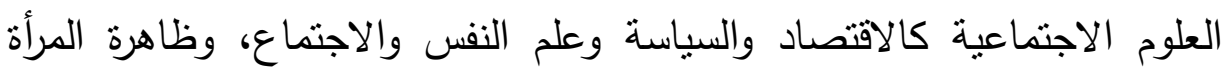
المعيلة ليست جديدة في المجتمعات الإنسانية فوجد حالات كثيرة من بقاء المرأة بمفردها وإدارتها لعائلتها ولنفسها، فهي تلك المرأة المطلقة أو الأرملة أو التي لئي هجرها زوجها، أو زوجة السجين أو زوجة المريض والفتيات اللاتي لم يسبق لهن

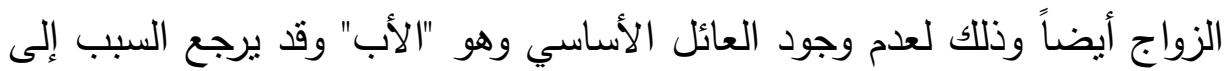

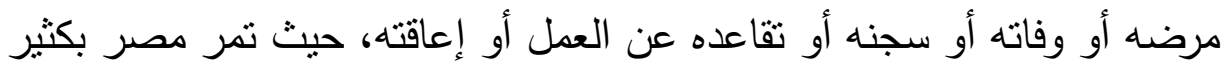

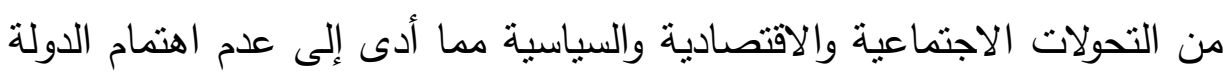

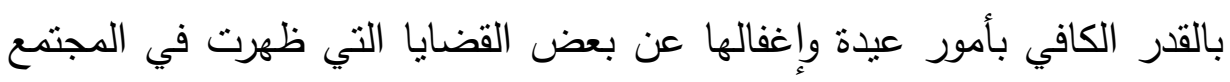

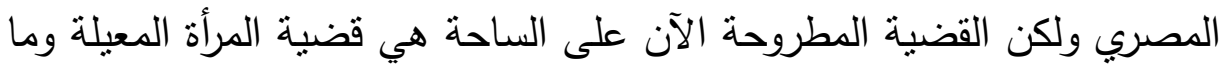
تعانيه من نقص في احتباجاها الأساسية، حيث أن اتساع الظاهرة في عصرنا

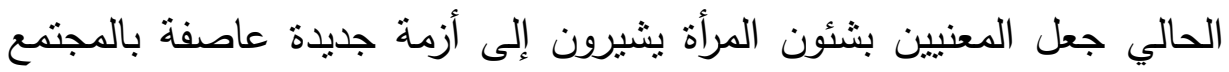
البشرى لها آثارها السلبية ليس على صعيد المرأة والأسرة بل المجتمع كله. ومع تدنى الأجور وانتشار البطالة تصاعدت الأهمية النسبية لهجرة العمالة مما

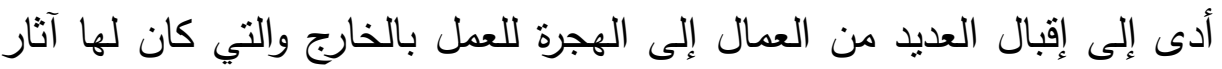

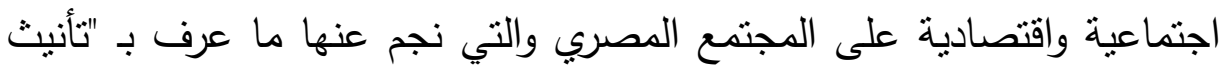
"Egyptian Family of Women” الأسرة المصرية ولنه 
ومع التغيرات العالمية المعاصرة، واتساع دائرة النشاط الاقتصادي وتطبيق سياسات الاقتصاد الحر الذى لا يعرف الحدود والحواجز بين الدول وتطبيق سياسات الخصخصة، نطورت برامج التكيف الهيكلي وما صاحب ذلك من إضعاف قدرة الحكومات على توفير الاحتباجات الأساسية للسكان، ولقد ظهرت لرته

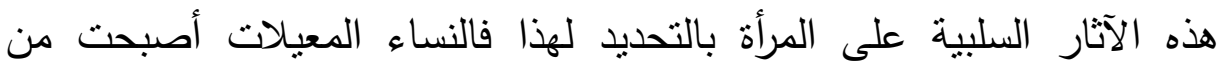
القضايا شديدة التعقد، لأن المرأة تعانى من الفقر وأيضاً تعول مما أدى لظهور ظاهرة "تأنيث الفقر Poverty or Women" والسبب في ذلك لأنها من أكثر الفئات حرماناً من التعليم، والرعاية الصحية، ونقص فرصنها في سوق العمل

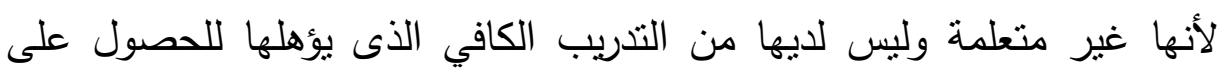
وظيفة بدخل شهري ثابت أو عمل بمشروع صغير .

للمرأة المصرية دور تاريخي متميز ، لقد تجلى هذا الدور في مشاركتها بشكل

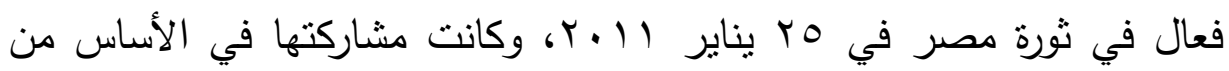
أجل مصر، ومن أجل الدفاع عن حقوق كل المصرين في الحرية والعدل والكرامة وتكمن ثورة مصر الحقيقة في قواها البشرية التي تعتبر من أهم الثروات على الى الى

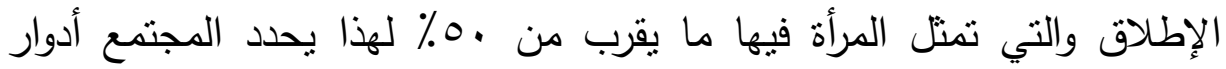
المرأة ومواصفات كل دور طالما تشغل المرأة مركزاً داخل البناء أو النظام الاجتماعي، ومن ثم تتعدد أدوار المرأة كزوجة وعاملة وأم وغيرها من الأدوار والمسئوليات التي يتوقعها المجتمع، ومن بين هذه الأدوار دورها كامرأة معيلة

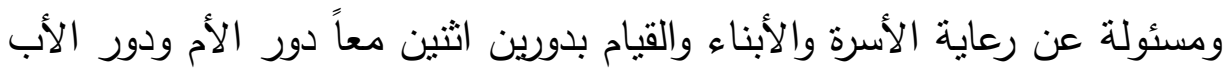

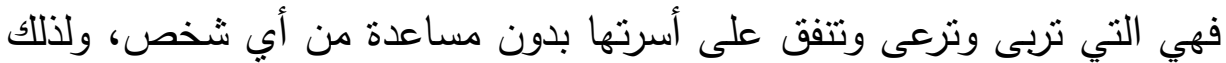

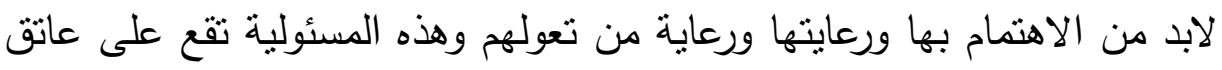
الدولة، والدولة تقوم برعايتها من خلال الجمعيات الأهلية. 


\section{ثانياً: مشكلة الدراسة:}

لقد حظيت قضايا المرأة في الآونة الأخيرة باهتمام على المستوى القومي فمن

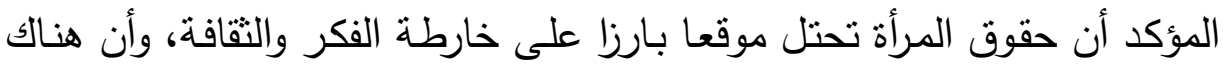

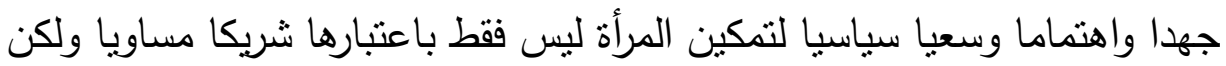

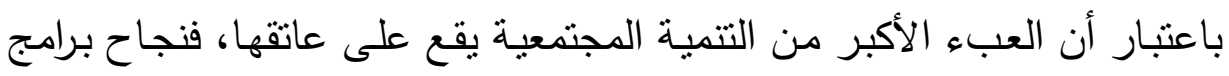
التتمية واستدامتها مرهون بمشاركة العنصر البشري وحسن إعداده وطبيعة تأهيله،

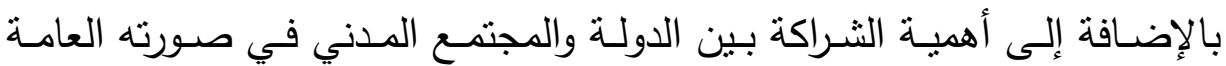
لتحقيق التمكين الكامل والثامل للمرأة. وعلى المستوى المحلى، قامت مصـر بدور ريـادي ملموس، وأظهرت نشـاطاً

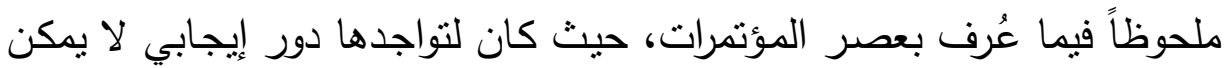

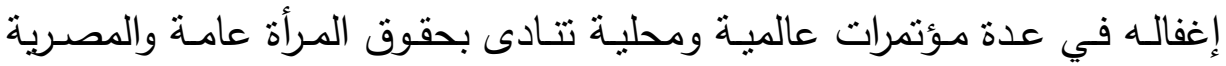

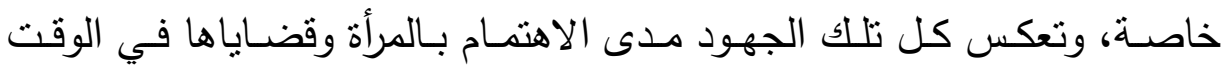
الحالي. (2) هذا و يشمل مفهوم " المرأة المُعيلة " العديد من النساء (الأرامل، المطلقات،

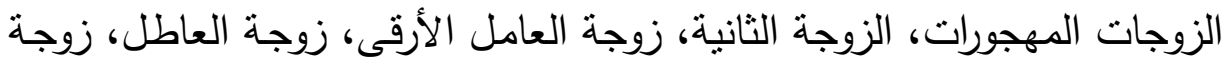

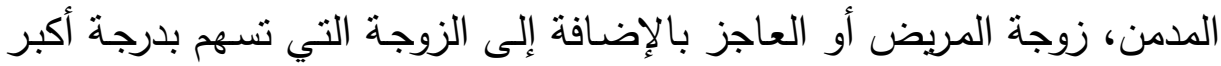

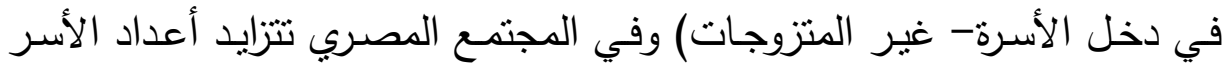

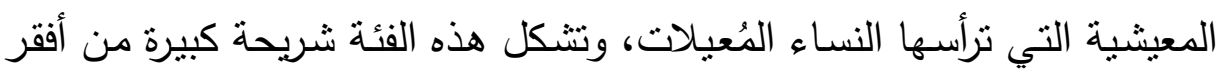
الفقراء حيث تقع المسئولية على المرأة في إعالة أفراد الأسرة من الصغار والكبار ،

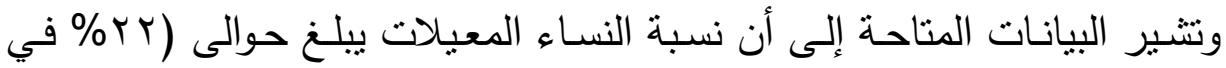
الحضر بينما في الريف Oب\%).

وحسب آخر الإحصائيات المتاحة حتى عام 1 ــ فإن نسبة المرأة المُعيلة

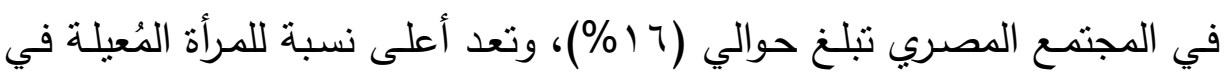




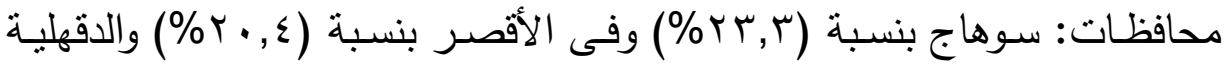

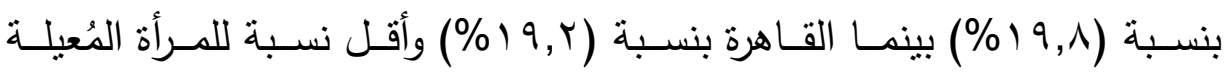

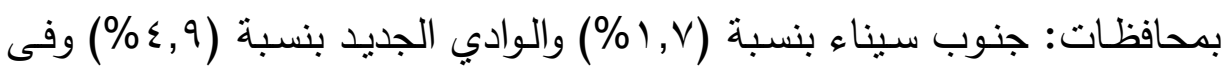

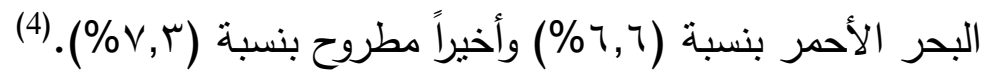
وتعـاني المـرأة المُعيلـة مـن العديد من المشكلات والصـعوبات الحياتيـة ومـن أهمها المشكلات الاقتصـادية حيث تتركز معظم النسـاء المُعبلات في الثـرائح

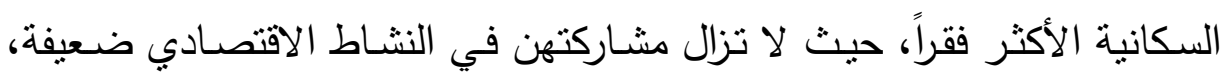

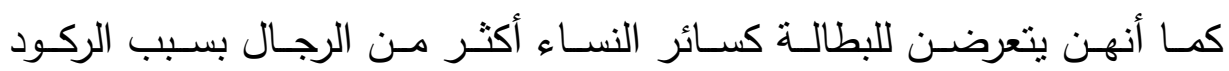

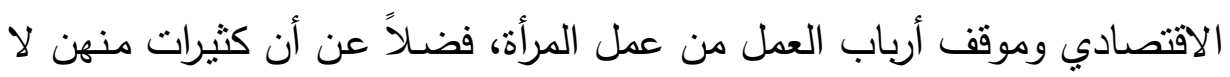
يستطعن الخروج إلى العمل لعدم توفر الخدمات المساعدة وفرص التدريب المهني التي تتوافر للرجال والتي يمكن أن تناعدهن في الحصول على عمل مناسب. ثالثاً: أهمية الدراسة:

تتمنل اهمية الدراسة الراهنة في جانبيها النظري والتطبيقي فيما يلي: أ- الأهمية النظرية 1-تأتى هذه الدراسة كضرورة أقرتها وأكدت على ضرورة إجرائها نتائج العديد من الدراسات والبحوث العلمية التي تتاولت مشكلات المرأة المعيلة لأسرة

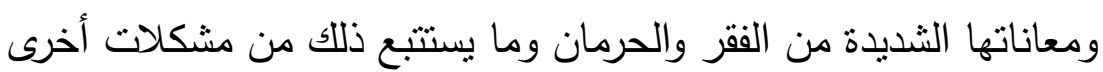
أكثر عمقاً. r-يعد انتشار ظاهرة المرأة المعيلة مقياساً لقياس فقر المجتمعات ويعاني أطفال

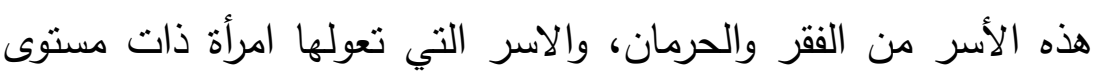
اقتصادي أقل من الأسر التي يعولها رجل.

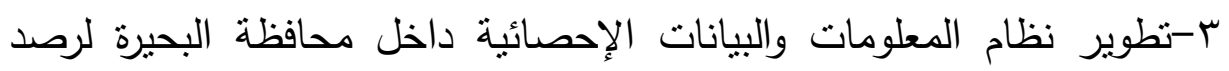
واقع المرأة المعيلة واحتياجاتها. 
ع-يمكن من خلال هذه الدراسة وضع تصور مستقبلي لمواجهة الأزمات التي

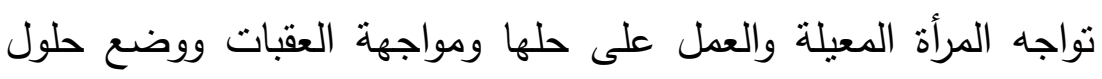
إيجابية لها بطريقة علمية.

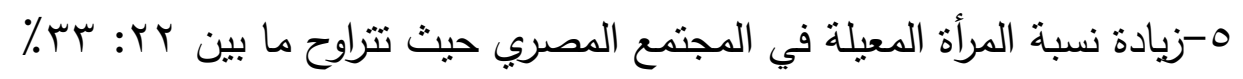

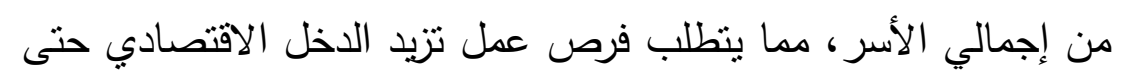
تتمكن المرأة المعيلة من إعالة أسرتها.

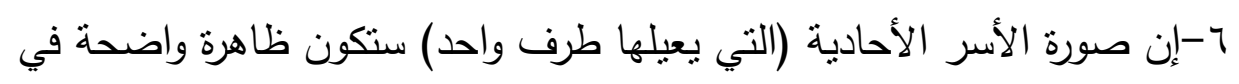

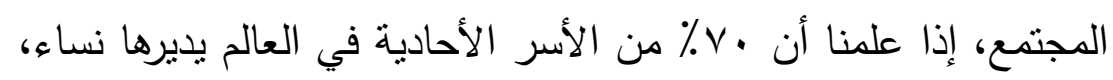

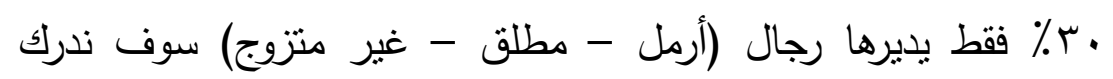
خطورة هذه الظاهرة الآخذة في الاتساع.

\section{ب-الأهمية التطبيقية}

1-تفعيل جميع الآليات في المجتمع المدني ليقوم بدوره في رفع المعاناة عن

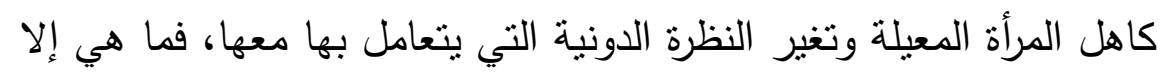

$$
\text { أخت أو ابنة أو زوجة أو أم لكل منا. }
$$

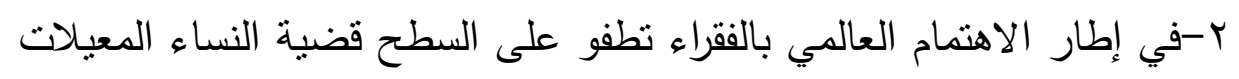

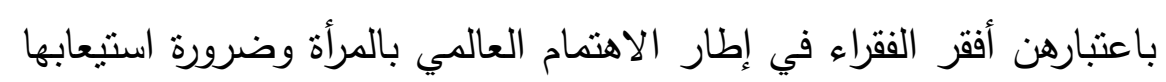
داخل خطة التتمية الإدارية.

r-أصبحت ظاهرة النساء المعيلات ظاهرة عالمية تقرض تحديات أمام جميع

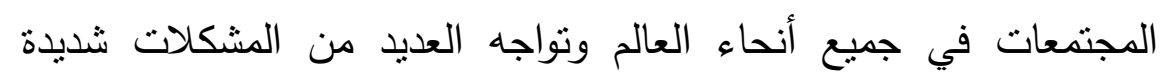

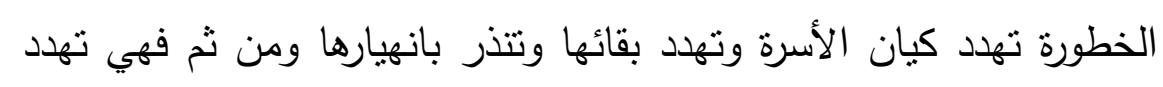
كيان مجتمع بأسره.

ع-المساهمة في حل المشكلات التي تواجه المرأة والتي تحول دون تفعيل باتهان

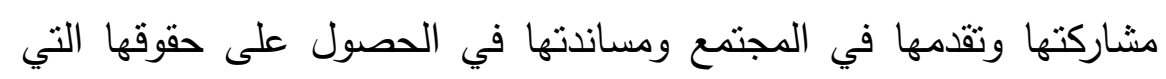


نص عليها الدستور والقوانين المصرية وما التزمت به مصر في الاتفاقيات الدولية.

0- تخفيف ما تعانيه المرأة المعيلة من مشكلات والعمل على تطوير ما يقدم للمرأة المعيلة من خدمات وذلك لرفع مستواها ومستوى أسرتها مع إبراز أهمية الدور الذي تقوم به سواء داخل الأسرة أو في المجتمع.

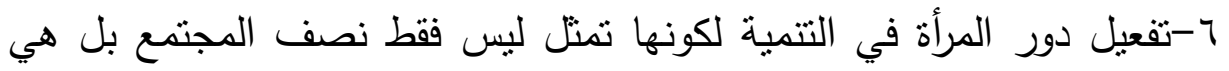

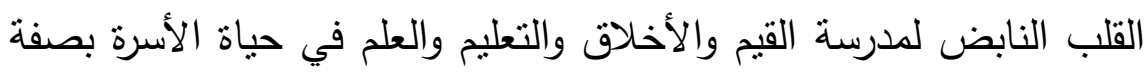
خاصة والمجتمع بصفة عامة.

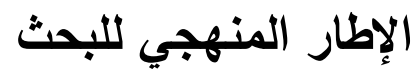

المنهج بمثابة الاستراتيجية أو الخطة العامة التي يرسمها الباحث لكي يتمكن من حل مشكلة بحثه أو تحقيق هدفه تعتمد على مجموعة من الأسس والقواعد الأوله والخطوات بيتقيد منها في تحقيق أهداف البحث أو العمل العلمي.

يمتاز المنهج بالدقة والموضوعية والحيادية والملاحظة والقياس والتصنيف

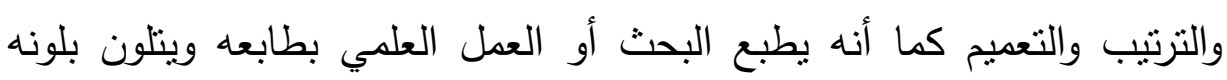
ويحدد وصفه وصفته على هذا الأساس.

فإذا كان البحث يحتاج إلى الاستعانة بقواعد الوصف فإنه ليجد بداً من

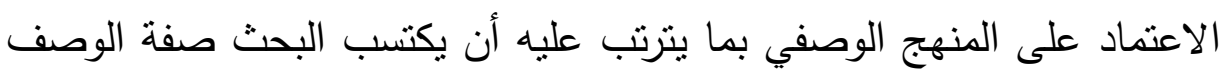

ويقال عنه بحث وصفى. (1)

وتعرف الدراسة الوصفية بأنها تتضمن دراسة الحقائق الراهنة المتعلقة بطبيعة

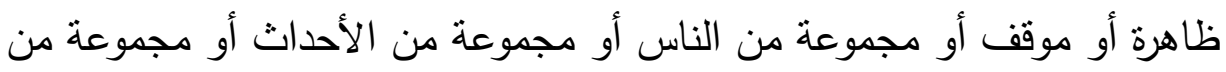

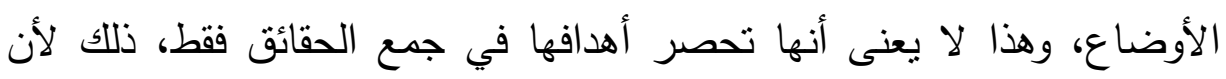

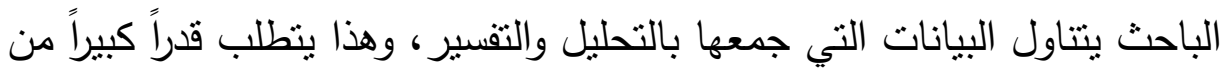

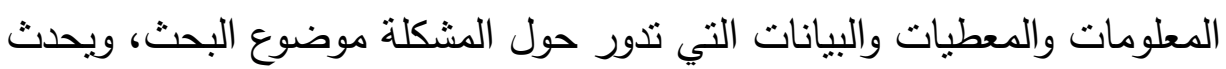


هذا من خلال الدراسات الاستطلاعية أو الكثفية التي تحدد الصورة العامة والإطار العام للمشكلة. كذللك فإن الدراسات الوصفية تحدد ما إذا كانت ظاهرة معينة تتكرر، وما إذا كانت في تكرارها مرتبطة بعوامل أخرى معينة، وتقوم

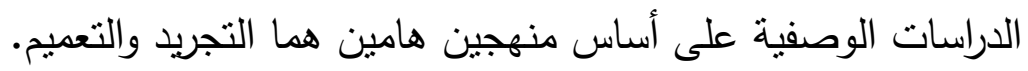
وبصفة عامة فإن أهمية الدراسات الوصفية ترجع إلى دقتها في اتساع

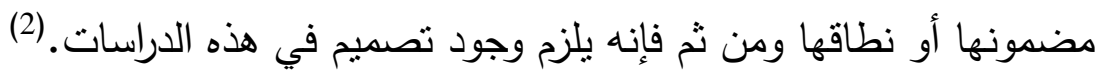
إذن إن أهداف البحوث الوصفية تتتوع وتتعدد بين دراسة خصائص السكان في

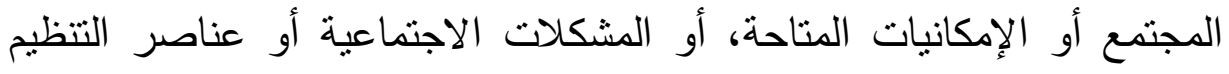

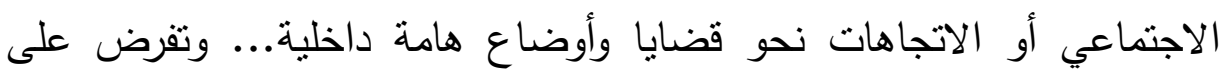

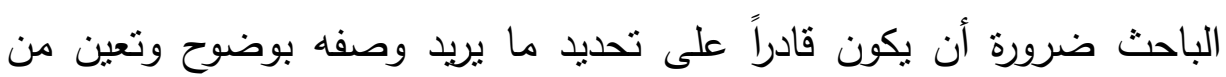

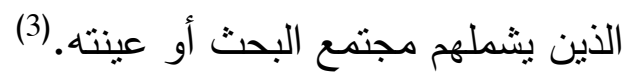
كما اعتمدت الباحثة على أداة الاستبيان والمقابلة الثخصية كأداة للدراسة.

\section{خامساً: النظرية الموجهة للبحث}

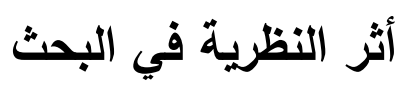

ا-توجيه النظرية للبحث نحو الموضوعات المثمرة.

r-تضفي النظرية على نتائج البحث دلالة ومغزى. r-تنطوي النظرية على توجيهات عامة "orientations" تمد البحث بسياق محدد. ع-توجيه مفاهيم النظرية وتصوراتها في عملية جمع وتحليل معطيات البحث.

\section{أثز البحث في النظرية}

1- بسهم البحث في تطوير النظرية.

r- يسهم البحث في إعادة صياغة النظرية.

r- يسهم البحث في إعادة تحديد محور اهتمام النظرية.

ع - يسهم البحث في توضيح مفاهيم النظرية. (1) 
لقد اعتمدت الباحثة على نظرية الدور كنظرية موجهة للدراسة. بدأت نظرية الدور تؤثز في الوقت المعاصر حيث أخذ عدد المؤسسات

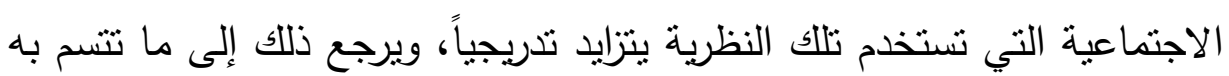

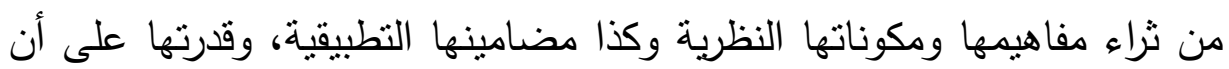

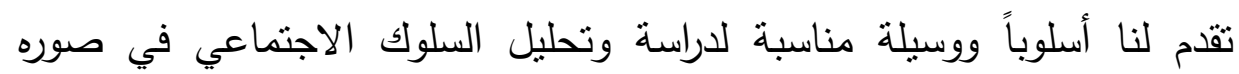
السوية والمشكلة. (2). - العناصر الأساسية لنظرية الدور هي: الدور Role: ويمنل وحدة الثقافة. الوضع Position: ويمثل وحدة المجتمع. الذات Self: ويمنل وحدة الثخصية. - إن نظرية الدور نتاج لجهد أنثخاص عديدين، ومن الرواد الأوائل الذين كان لهم

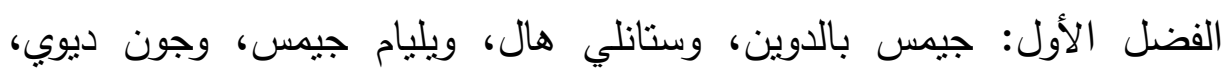
وتشارلز هـ. كولي، وجورج هدميد، وذلك في مطلع القرن العثرين. -وقد يعرف الدور بأنه المطالب المعينة بحكم تركيب الجماعة والمرتبطة بوضع فئع

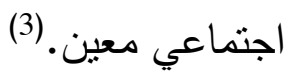
مفاهيم نظرية الدور

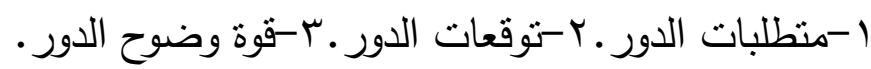

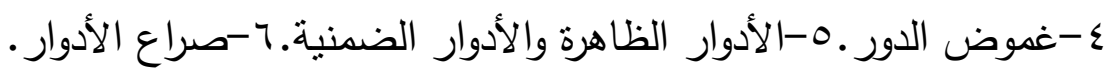

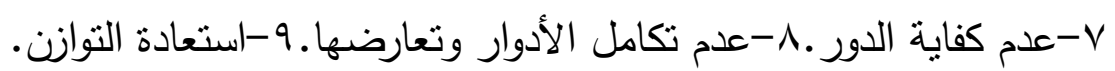

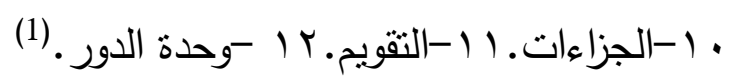
ونظرية الدور تساعد الباحث على فهم المجتمع البشرى فى صورة كلية وإعطاؤه

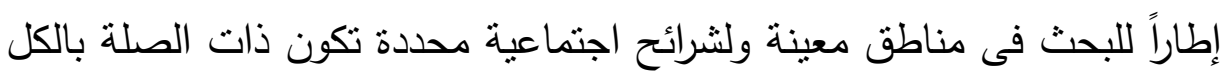

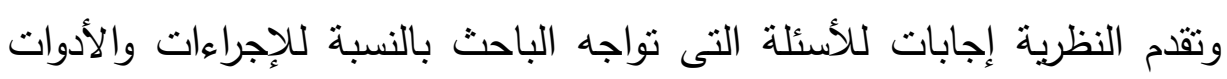


المنهجية الملائمة لطبيعة موضوع الدراسة، وتحديد نطاقها وفئاتها، وتحديد الأساس العلمي للتحليل والتفسير لنتائج الدراسة التطبيقية فى علم الاجتماع. (2) سادساً: الإطار النظري للادراسة:

\section{أولاً: التطور التاريخي لظاهرة المرأة المعيلة.}

-مكانة المرأة فى المجتمع المصرى القديم

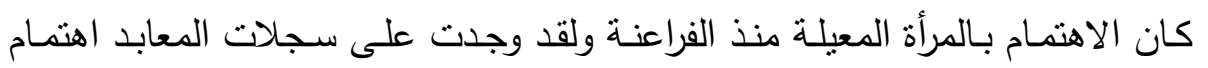

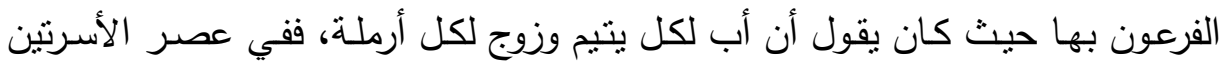

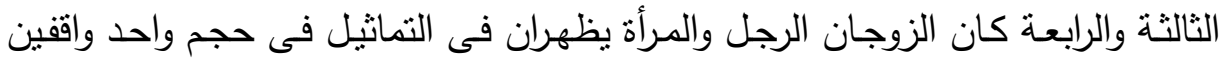

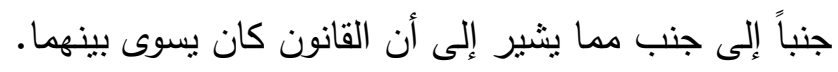

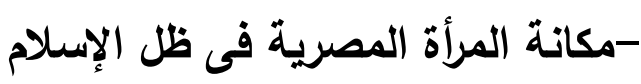

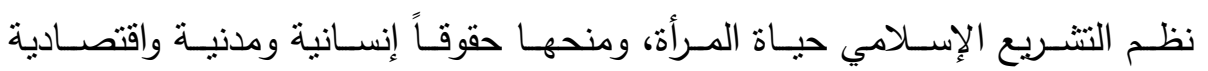

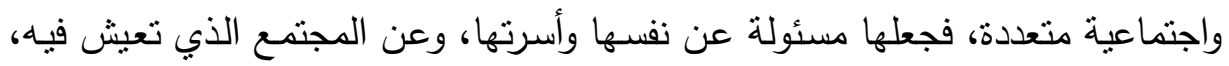

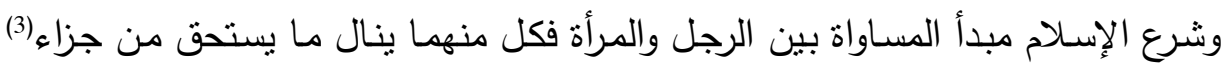

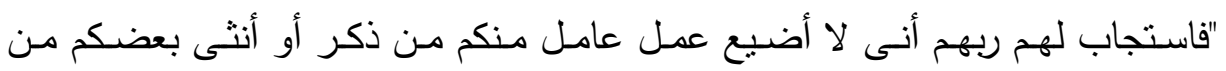
بعض" ويحمل كل منهما مسئوليته عامة "كل امرئ بما كسب رهين".

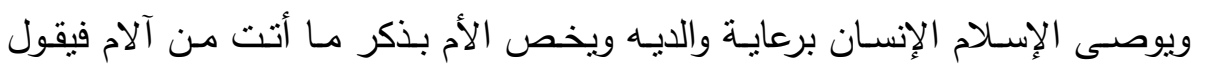

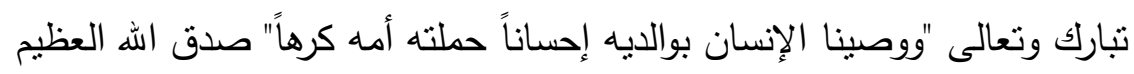
-المرأة فى المجتمع المصرى الحديث المين

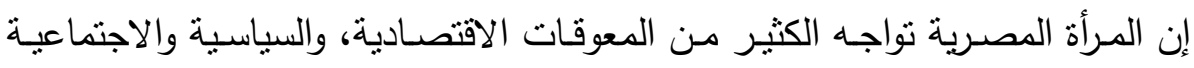

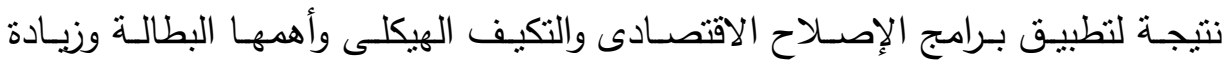

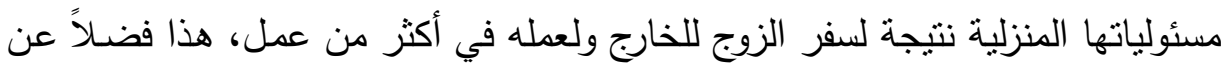

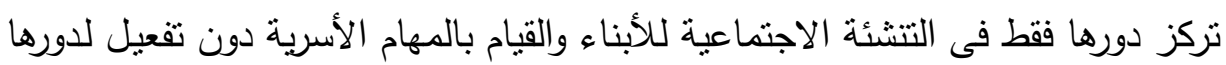

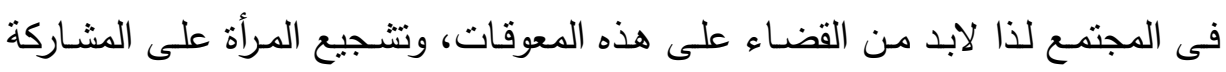

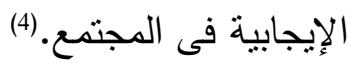


وهنالك العوامل الاقتصادية وأهمها الفقر "Poverty" الذي يعد بحق حجر الأساس في

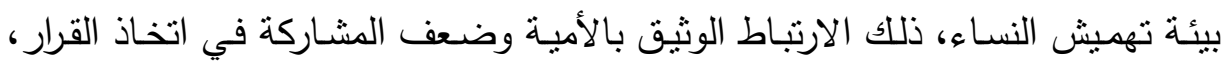

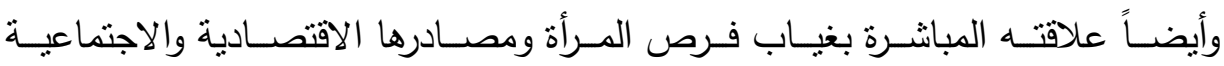

والسياسية.(5)

\section{ثانياً: الأسباب الرئيسية لانتشار ظاهرة المرأة المعيلة}

ا-ترمـل الزوجـة: الأرامـل السيدات هن من فقدن الزوج بسبب الموت ولم

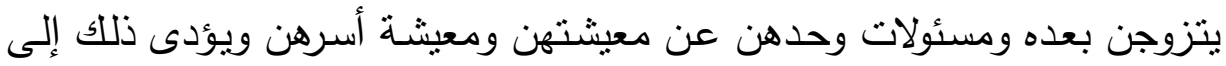

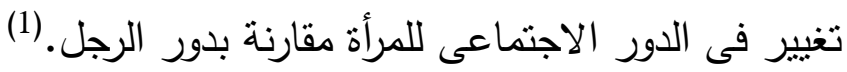
Y -الطـلاق: الطـلاق سبب رئيسى وأساسى فى التقكلك الأسـرى وإنحراف الأبنـاء وذلك لأن هناك افتقاد الرعاية الوالدية وبالتالى فإن الطلاق يسبب العديد من المشكلات

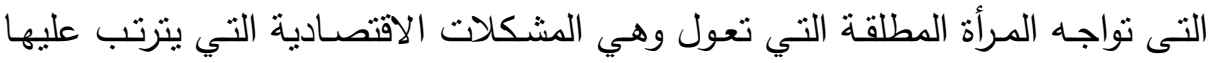

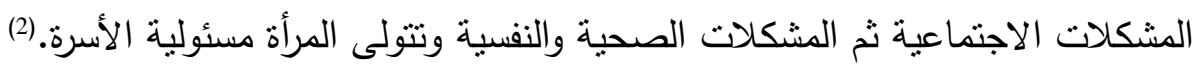

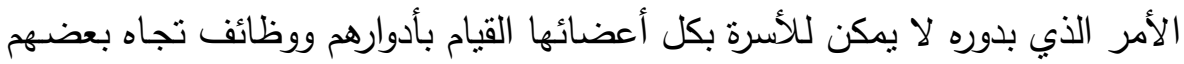

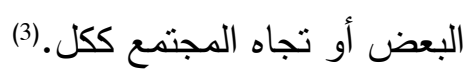

ب-التقاعد: يُعرف الثقاعد بصفة عامـة على أنه "انسحاب أو انفصـال من العمل

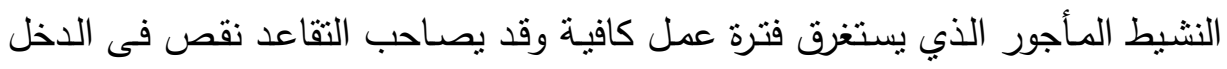
وشعور المتقاعد بعدم قيمته وأنه أصبح مستهلكاً غير منتج، وإذا أراد العمل بعد نقاعده فإنه يواجه بعض المشكلات حيث فرص العمل المناسبة أقل وتضطر المرأة إلى إعالة أسرتها. (4) يشير (1970) إلى أن التقاعد قد يكون مقبولاً إذا تمتع الزوج بصحة جيدة وبوضع اجتماعى واقتصادى منوسط أو عالى وقد يكون غير مقبول

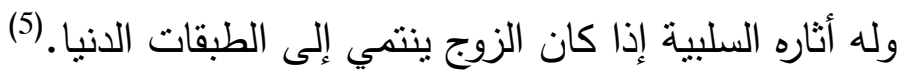
ع -الزوجـات المهجورات: إن الآثار الاجتماعية للهجرة والتي نجم عنها مـا

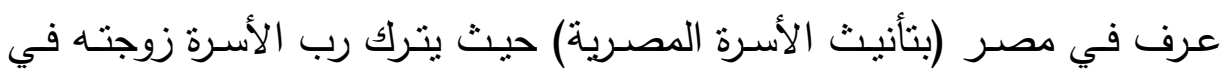

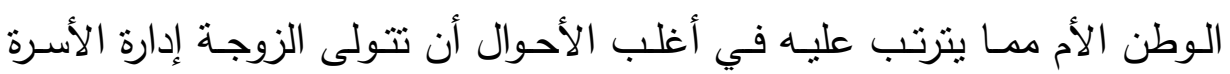
Doi: 10.12816/0041728 
بصورة كاملة بما في ذلك الأطفال الذين ينشئون في ظل عائلات وحيدة الوالد أو

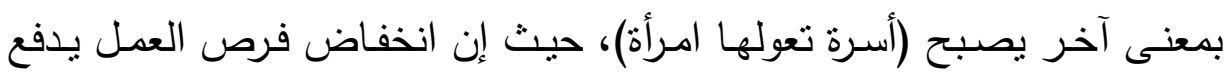

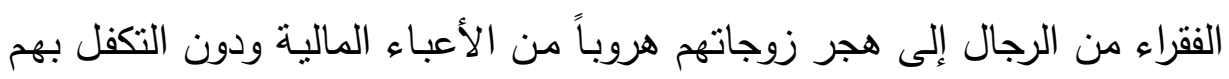

مادباًا. (6) مبراء

ه-زوجات رجال عاطلون عن العمل: هن زوجات رجال في المعاش أو رجال

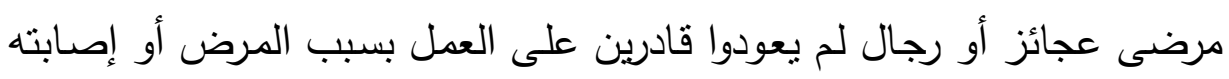

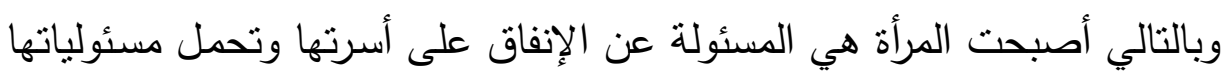

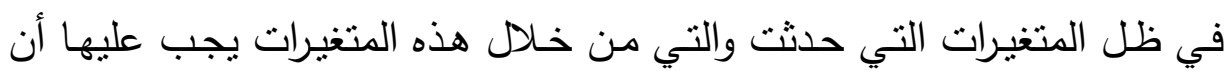
تنواءم معها لسد احتياجاتها واحتياجات أسرتها.

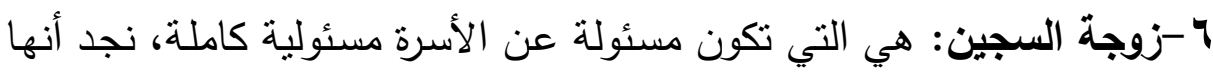
تنقد الإحساس بالتوافق، فقد لوحظ عليها صورة الذات سيئة ومطحونة وضعيفة نتيجة القهر الاجتماعي الخارجي بالإضافة إلى الضغوط الاقتصادية.(2)

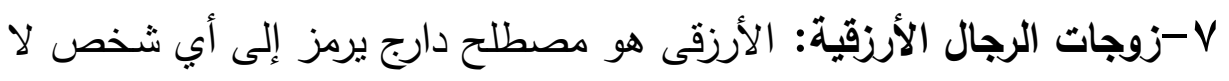

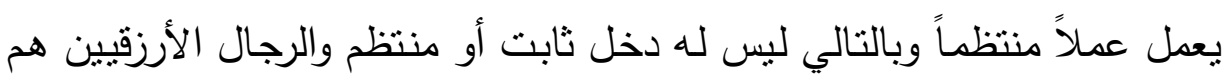

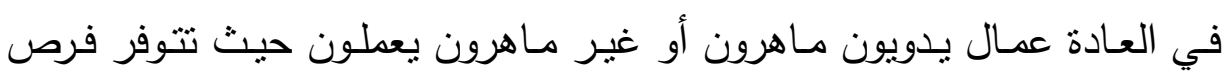

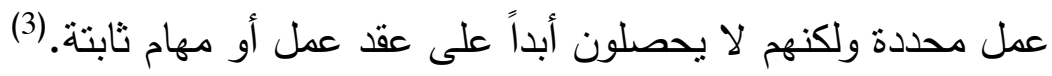
1-زوجات مدمني المخدرات والكحول: تعتبر زوجات مدمني المخدرات من أكثر العرات

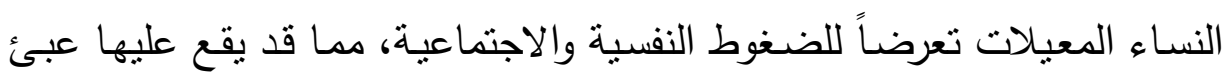

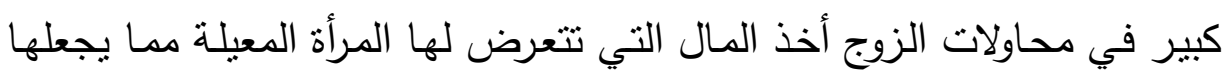

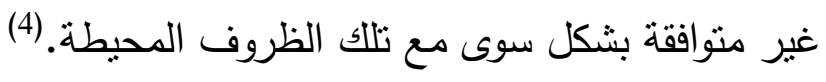
9-النساء اللاتي لم يسبق لهن الزواج: النساء اللاتي لم يتزوجن أبداً ويمثلن

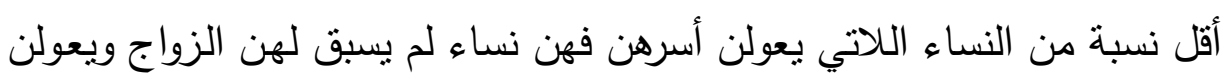


أسرهن وتقوم فيه المرأة بتحمل مسئولية الأسرة التي تعيش فيها لسد احتياجاتها واحتياجات أسرتها. (5)

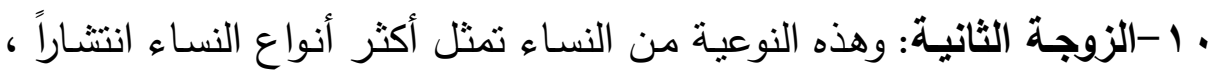

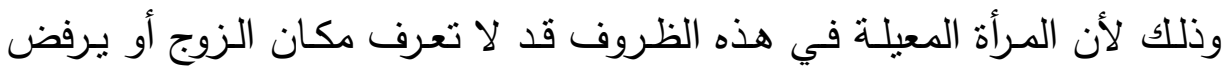

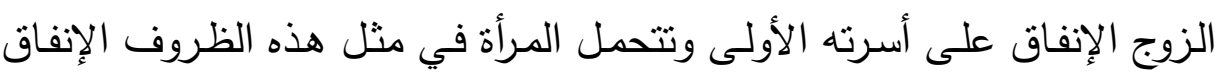
على أسرتها. 1 | 1 -الزوجات اللاتي يساهمن بلخل أكبر في الأسرة: هن النساء المتزوجين من

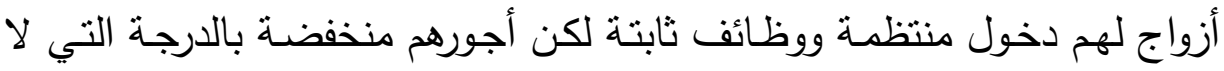
تسمح لهم بتغطية احتباجات المنزل، فتقوم المرأة بالإنفاق على الأسرة حيث أنها تحصل على دخل أعلى من دخل الزوج وتصرفه في احتياجات المنزل. (1) r ا النساء المتزوجات من رجال مرضسى ومصابين بالعجز : هن نساء زوجات

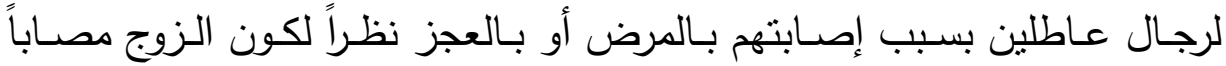
بمرض خطير فالنسـاء المتزوجات من رجال في مثل هذه الظروف هن نساء

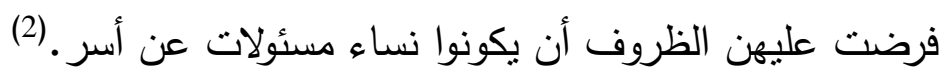

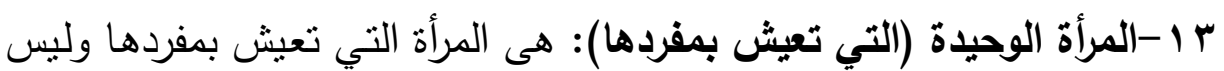

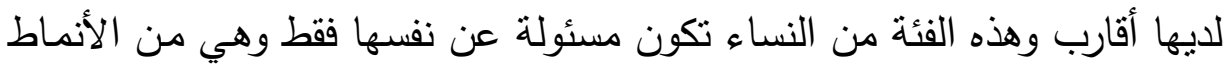

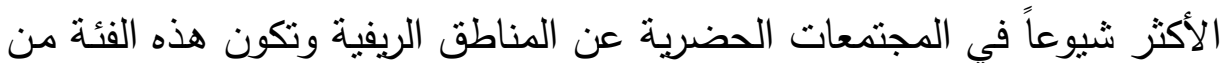

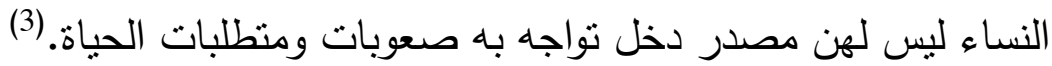
؛ ا-الإصـلاح الاقتصـادي : لقد اتبعت مصر شـان عدد كبير من الدول النامية برنامجاً للتدريب والتكيف الهيكلي لبرنامج الإصلاح الاقتصادي بالاتفاق مع كل

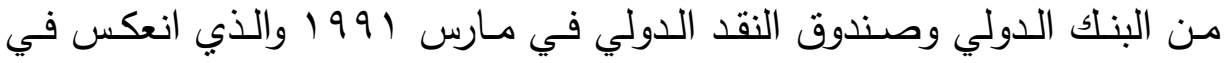
معدلات التضـخم وزيـادة الدين الخـارجي ولهـذا شـهدت أعداد النسـاء الفقيـرات والمعيلات لأسـر في المجتمع المصـري تزايـد بسبب نقص بـرامج المســاعدات

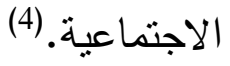


ها-الهجـرة الخارجيـة : رصد علمـاء الاجتمـاع في مصـر الآثار الاجتماعيـة

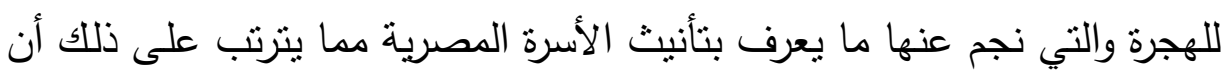

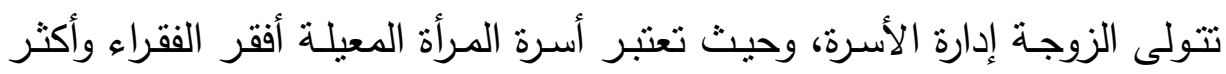

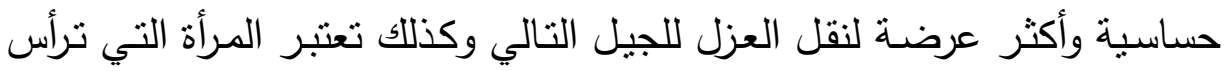
الأسرة وصمة عار . (5)

17 - 1 -تنفيذ خطط للتنمية الاقتصادية والاجتماعية لإحداث التقدم في المجتمع: نظراً لقيام هذه المجمعات بإنشاء المصانع والمشروعات التتموية الأخرى والتي

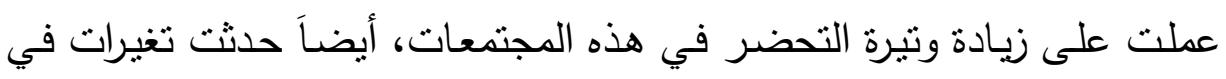

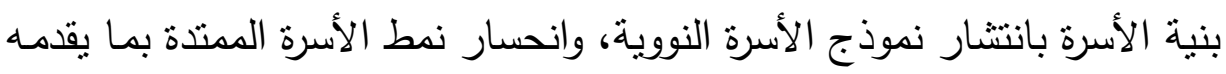

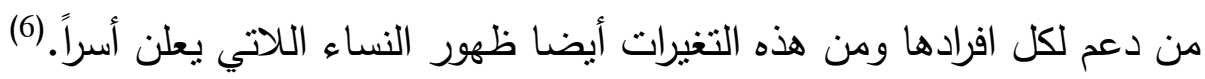
I V العولمة Globalization : العولمة لها جوانبها الإيجابية في فتح الحدود وتقريب المسافات وجعل العالم قرية كونية واحدة وأيضاً لها جوانب سلبية، حيث الهابه ترتفع نفقات وتتخفض الأجور ، ومن ثم يقل الإنفاق على نصيب الفرد من العلاج

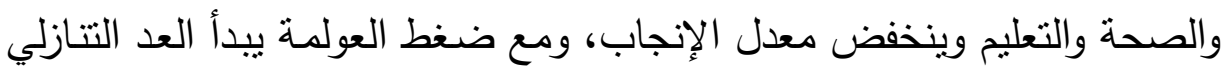

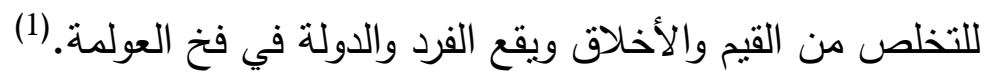

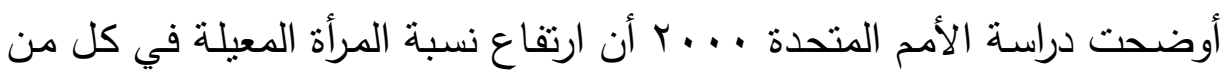
لبنان وفلسطين نظراً لفقد رب الاسرة في الحروب أو مرضه أو هجرته ويؤثر ذلك ألك

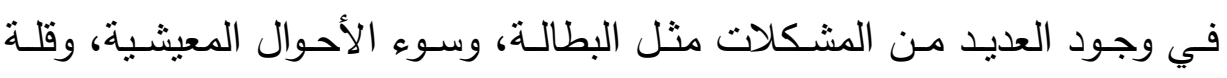
الاخل، وصعوبة توفير الرعاية المطلوبة لأسرهن. (2) ثالثاً: سمات وخصائص النساء المرأة المعيلة: ا-تتميز هذه الفئة من النساء بكبر السن حيث أن متوسط عمر المرأة

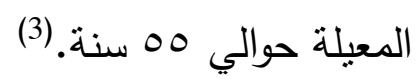

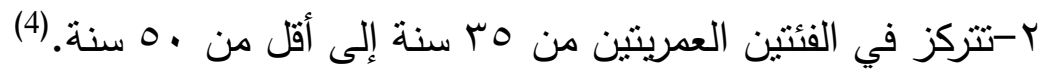

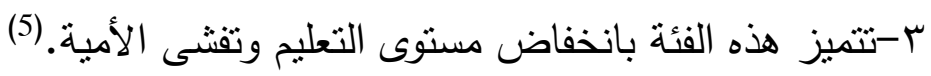


ع-ارتفــاع معـدل انحـراف الأحـداث فـي الأسـر الفقــرة ذات الــخل

المنخفض، وخاصة تلك الأسر التي تعولها إمرأة. (6) التهات

0-ضعف المستوى المهارى للنساء المعيلات، وصعوبة تلقينهن تدريبات

لتتمية المهارات وبالتالي فإن أغلبهن فقيرات. (7)

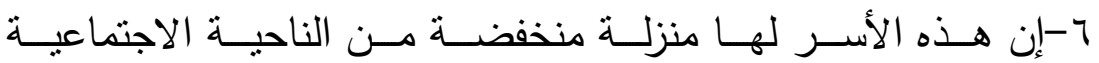

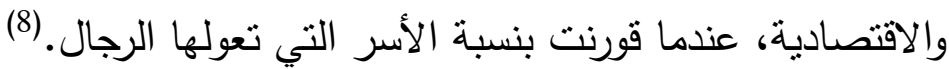

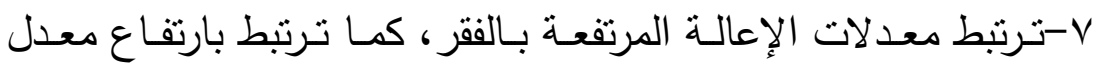

استهلاك الاخل ووجود عدد أكبر من الأطفال.

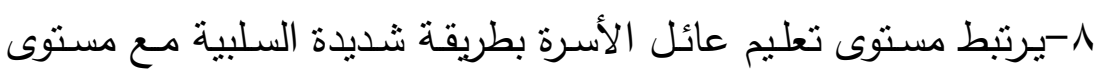

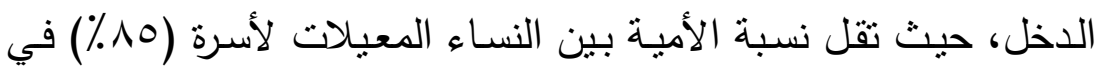
الريف و (0V\%) في الحضر في المجتمع المصري. (9) 9-الاغتراب وببساطة هو أن يفقد الإنسان ذاته أي أن يصبح غريباً عنها فئه

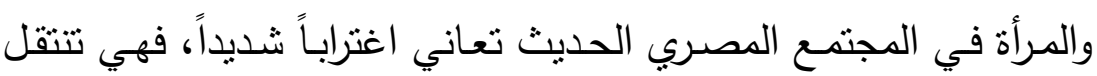

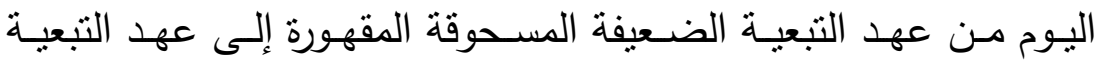
المبدعة القوية، وهي في حيرة وأزمة إزاء خلط الأدوار الذي وضعت فيه.

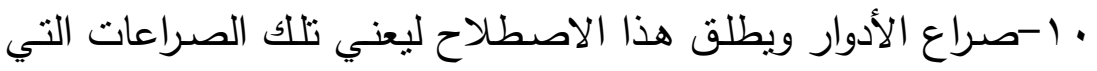
يدركها الأفراد المتعرضون لها، ويرى "سيبجل" أن هذا الاصطيلاح يشير إلى ذلك الموقف الذي تقع فيه الأنا في اختيار صعب أو مستحيل بين دورين مختلفين. (1) الإن الأم الوحيدة قد تشـعر بالوحدة أو بأنها حبيسـة أو حزينـة في بعض الأوقات، كما قد تتفث عن مشاعرها على الطفل، والأمر الهام هو الهو

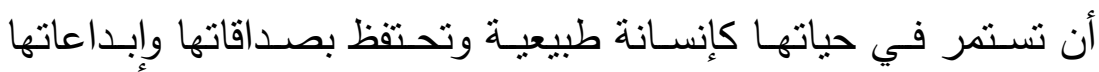
ومستقبلها المهني وأنشطتها الخارجية على قدر الإمكان ولا تسمح لحياتها 
أن تتحور حول طفلها فحسب، خاصة لو أن لديها طفلاً صغيراً يحتاج

إلى الرعاية وليس حولها من معين.(2)

Y Y - إن واقع العمالة النسائية يكثف عن جوانب هامة لضعفهن في سوق

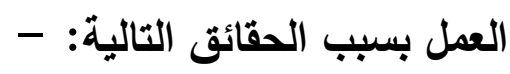

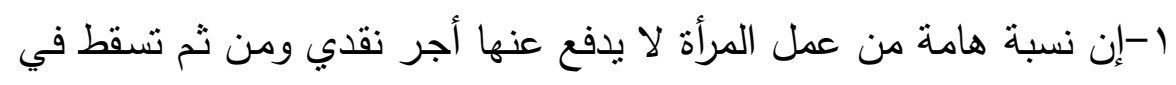
الاعتبار في حسابات الدخل القومي.

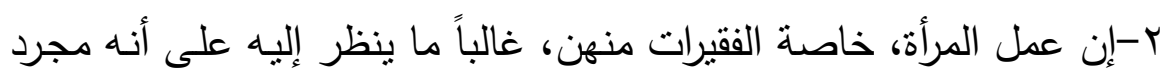

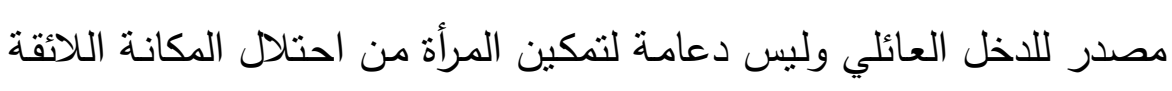

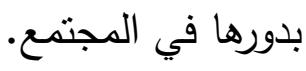

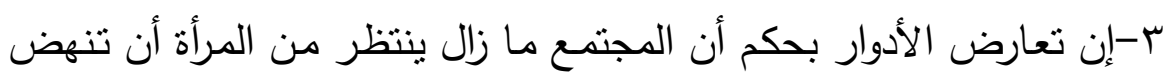

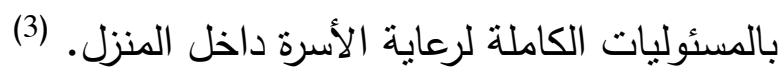

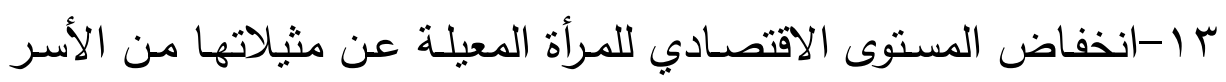
الني يعولها رجل خاصة بعد أن زادت عليها الأعباء وانتقالها من الرفاهية الإنية

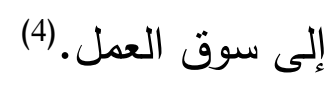

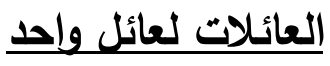

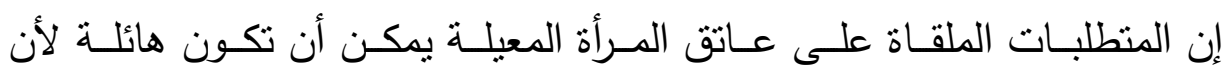
المسئولية سوف تكون على أكتافها هي فحسب، والمرأة التي تواجه وطأة كونها

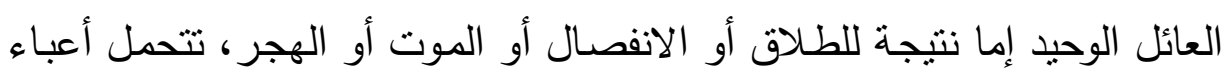

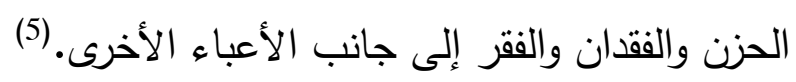

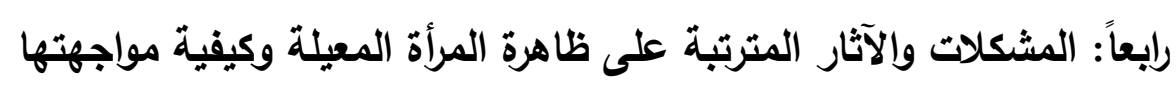

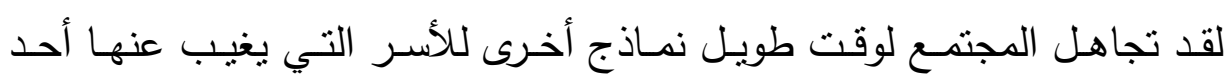

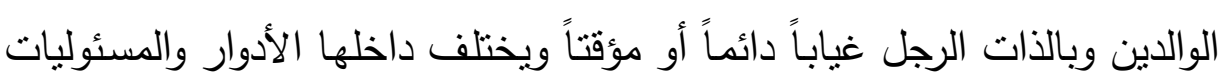

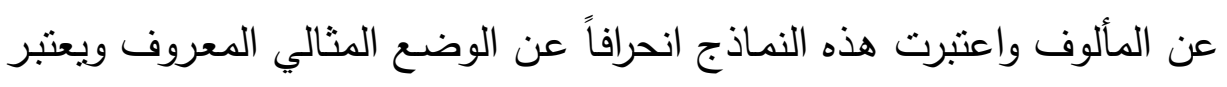


هذا انتهاكاً لحقوق الأطفال بها، وبشكل عام ينخفض مستوى المعيشة في الأسر

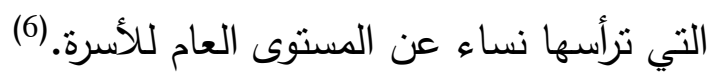

ا ا-العنف ضد المرأة

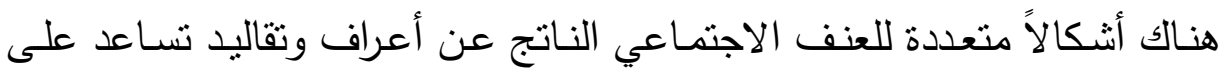

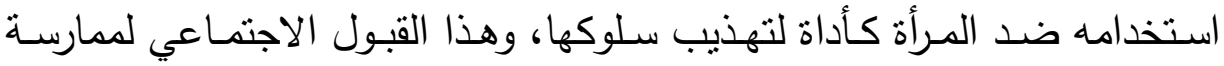
العنف ضد المرأة تكمن جذوره في بعض أساليب التنشئة الاجتماعية وهذا العنف

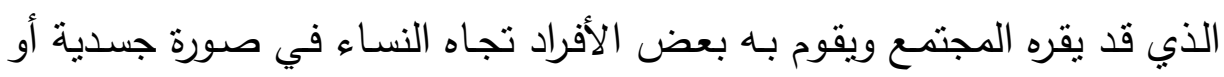

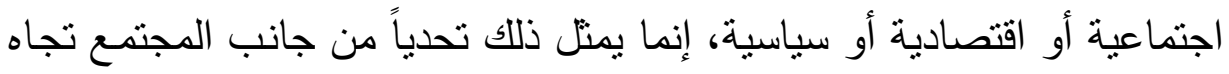
محاولات النهوض بالمرأة وتمكينها. (1) ويمكن تمكين المرأة اجتماعياً ونفسياً وقانونياً من خلال ما يلي: أ-توعية المرأة بحقوقها وبسبل الحصول علئهاعيا. ب-تيسير إجراءات التقاضي حال الوصول لهذه المرحلة.

\section{r r المشكلات الاقتصادية}

منذ أن ظهر مصطلح تأنيث الفقر (Feminization Poverty) لأول

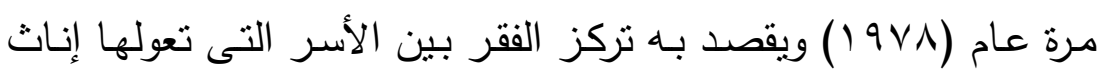

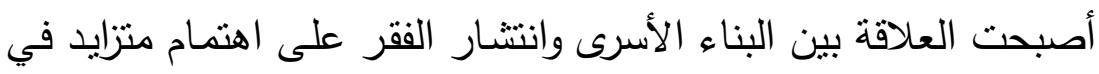
العلوم الاجتماعية. (2)

\section{ب- المشكلات الثقافية}

الأمية لم تعد مشكلة فردية تخص المواطن الأمي وإنما ظاهرة اجتماعية تخص

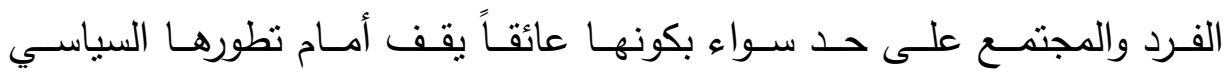
والاجتماعي والاقتصادي ويحول دون مواكبته لحضارة العصر الذي نعيش فيه. (3)

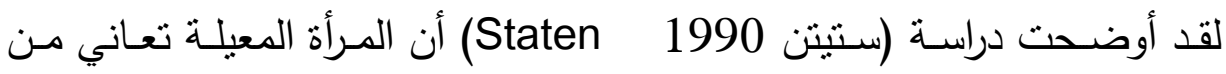

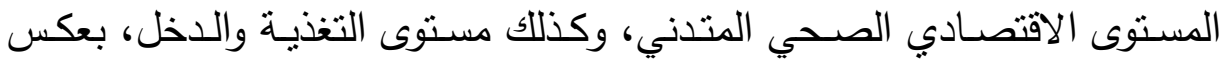
الوضع بالنسبة للرجل المعيل للأسرة. 


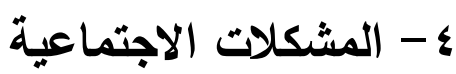

ويشير (Perez, 2000) إن النساء المعيلات لأسر يعانين من الثعور بالعزلة

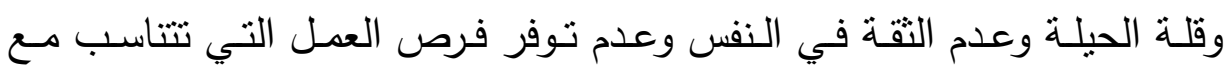
أدوارهن الجديدة كمعيلات لأسرهن ويؤثر ذلك بشكل ملحوظ على أدائهم لدورهم

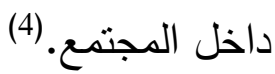
وتجد النساء المعيلات أنفسهن موصومات اجتماعياً لكونهم وحيدات، كما تستبعد النساء من شبكات المعلومات الاجتماعية وبرامج الدساعدة والدساندة الاجتماعية والخدمات الحكومية إذا لم يوجد رجل معهن. ه - المشكلات النفسية

تعاني المرأة المعيلة من نظرات الإثفاق من قبل الآخرين، مما يشعرها بالذل

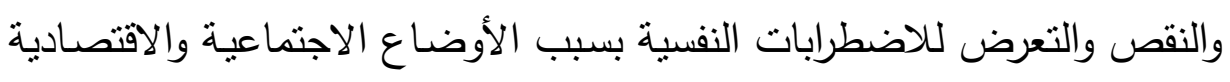
الثديدة وهدم الأرضية النفسية القادرة على مواجهة الأحداث والرغبة في العزلة الألة الألية

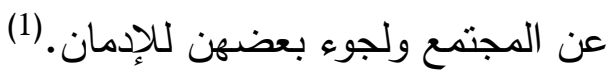
ب-المشكلات الصحية

تقنقر مساكن النساء والعائلات لأسرهن إلى خدمات البنية الأساسية من صرف

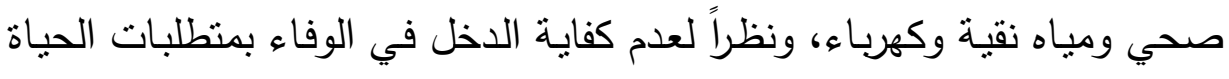

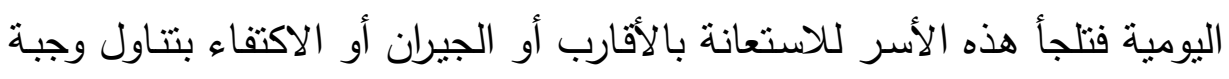

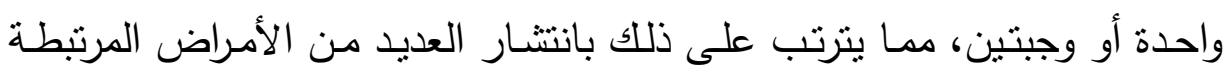

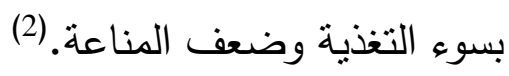

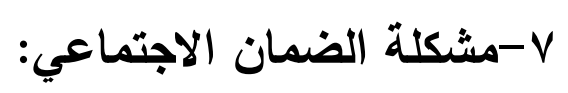

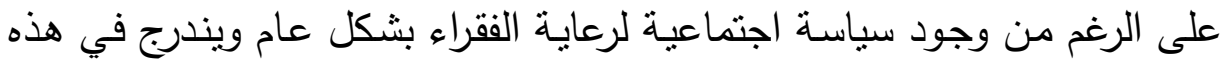

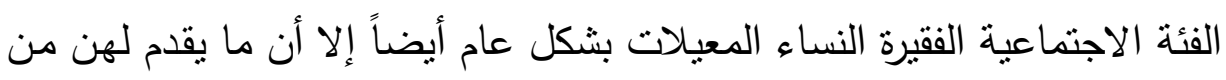

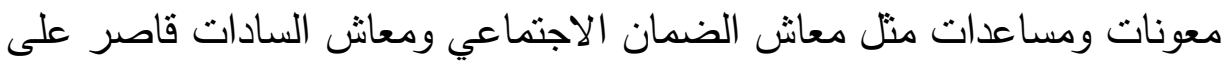

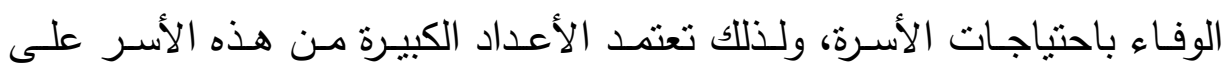
$\varepsilon \cdot r$ 
الإعانـات والمســاعدات التـي يقـدمها أهـلـ الخيـر والجمعيـات الأهليــة غيـر الحكومية. (3)

\section{1-مشكلات صراع الأدوار}

هنالك تتوع في أدوار المرأة التي تعول أسرة وهذا التتوع ليس داخل الأسرة بـل

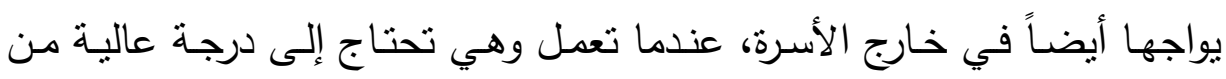

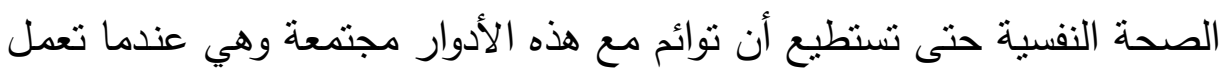
ترضى بالوظائف ذات الدخل المنخفض.

\section{9-مشكلات قانونية}

إن المرأة تواجه كثير من المعاناة في الحصول على ما كفله لها القانون من نفقة

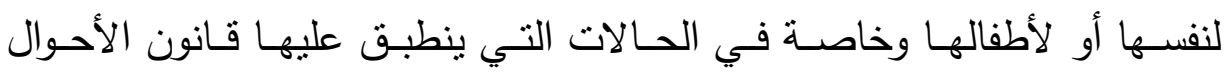
الثخصية، كما أن القوانين والتي تتـمل برامجها بعض فئات النساء والمعيلات

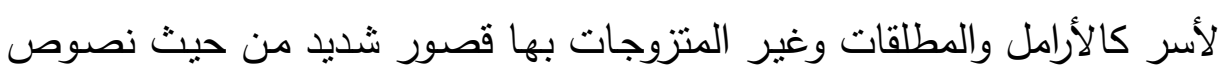
القانون نفسه أو تطبيقاته. (5)

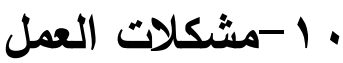

يرى البعض أن خروج المرأة للعمل انتقاصاً من حقوق الطفل الطبيعية في عناية

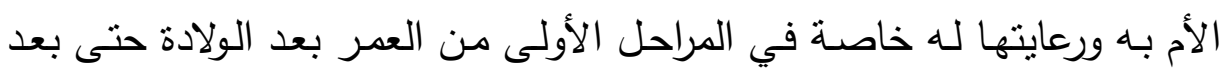
التحاق الطفل بالمرحلة الابتدائية. (1) -لقد أوضحت إقبال الأمير أن أهم المشكلات التي تعاني منها النساء العائلات

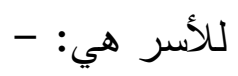

1-الافتقار إلى أجور ثابتة يمكن أن تفي باحتياجات الأسرة، وحتى المعاشـات

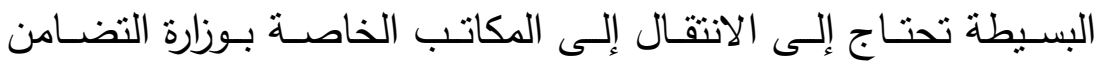

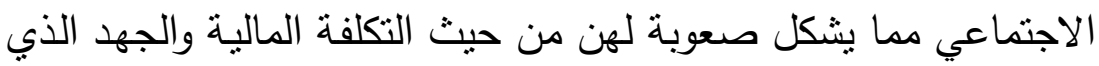
لا نستطيع كبيرات السن أن تقمن به. 
ץ-حرمان الأبناء فيها من التعليم خاصة الفتيات ودفعهن للعمل للحصول على دخل إضافي يمكن أن يساعد في مواجهة نفقات المعيشة.

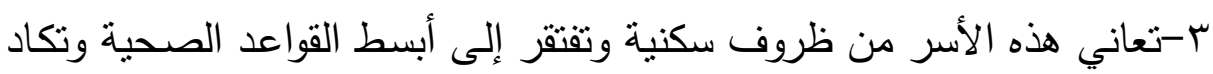

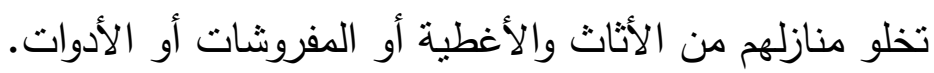
ع -لا تتمتع النسـاء اللاتي تعـولن أسـر بـالمميزات التي تمكنهم مـن الالتحساق

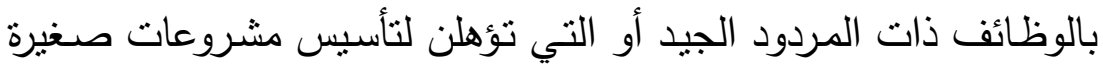

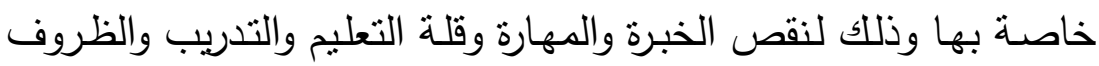

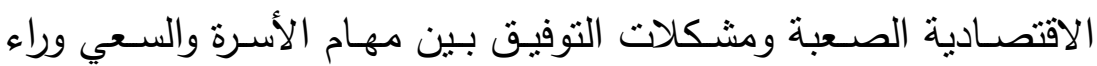
الرزق. (2) 0- صـوبة حصـول المـرأة التي تعـول على حقها وحـق أولادهـا الذي يكفلـه

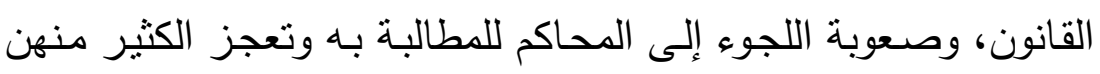
من الاستعانة بمحاكم تساعد على ذللك، كما تعجز عن تدبير التكاليف المالية اللازمة لرفع قضايا النفقة والطلاق.

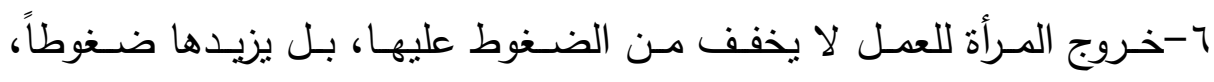
بالإضـافة إلى أنها تقوم بالأعمال المنزلية بكافة أنواعها ورعاية أولادها،

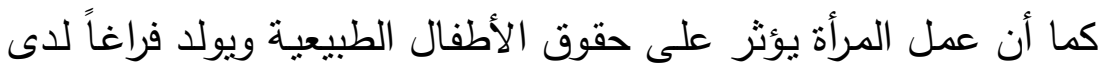
الأبناء.

V-تواجـهـ النسـاء اللاتـي تعـولن أسـر عقبـات مؤسسـية ضـخمة وهـي عـدم

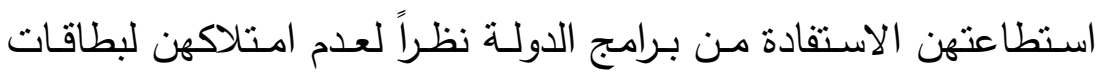

شخصية. (3)

\section{مشكلات الأمبية}

إن أمية المرأة المعيلة يؤثر في المستوى التعليمي لأبنائها، حيث أثنادت دراسات 1991 "'Weng Winifred Fin Egan اقل في المستوى التعليمي مقارنة بالأسر التي يعولها رجل.(4) 


\section{كيفية مواجهة مشكلات المرأة المعيلة)(1):}

لتوسيع إمكانيات استفادة المرأة بشبكة الأمان الاجتماعي ومواجهة مشكاتهاتلاتها:

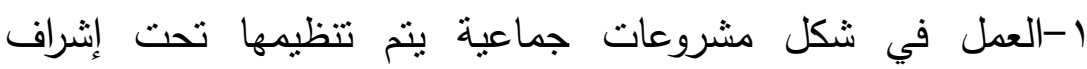

$$
\text { الجمعيات الأهلية. }
$$

r- تبسيط إجراءات طلب الحصول على الاتثمان.

$$
\text { r- ك-تيسير شروط الإقراض قصير الأجل. }
$$

ع-الاهتمام بالبرامج التدرييية التي ترفع من قدرات النساء في الحصول على

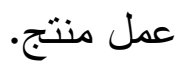

ه-بذل جها لتشجيع مزاولة النساء للأعمال التجارية الخاصة، وتزويدهن

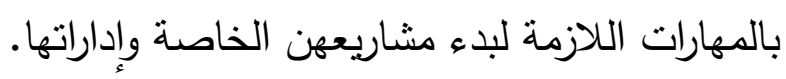
4-توسيع تجربة جميعه رجال الأعمال بالإسكندرية والبنك الوطني للتنمية.

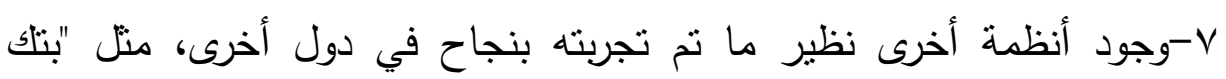
جراميين" في بنجلادش وغيرها. ^ - معالجة مشكلات عمل المرأة في القطاع غير المنظم، والتي ترتبط بالتسويق والتمويل والتنريب. وربما يستدعي مناقثة هذه القضية التأمل وإعادة النظر في المادة رقم (1) (1) من الدستور المصري والتي تتص على أن "الدولة تكفل التوفيق بين واجبات المرأة

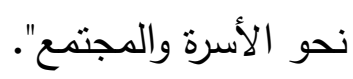
9-تعد الصناديق الاجتماعية من الأنشطة التي أثتبت جدواها في الوصول الى

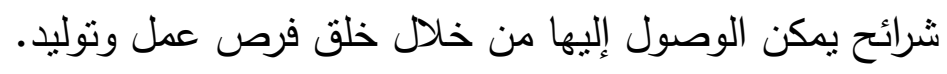

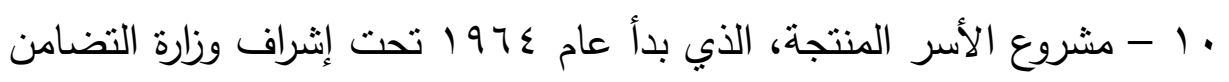

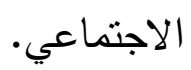
1 1-مشروع الأندية النسائية والتي تعتبر مراكز للتنريب على المهن المختلفة. 


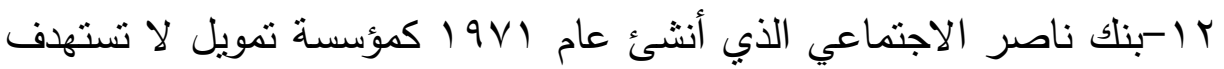
الربح. rا-نظام معاش السادات الذي أنشئ عام ،191 ليعطي غير المستقيدين من أي نظام معاشات. ع ا-الضمان الاجتماعي الذي يعطي الأرامل، واليتامى وعائلات المسجونين والعاجزين عجزاً كلياً، وغيرها.

\section{خامساً: العلاقة بين الفقر والمرأة المعيلة:}

يمثل الفقر التحدي الأول الذي يواجه العالم اليوم، ويوصف بأنه انتهاك لحقوق

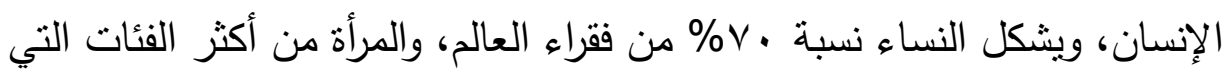

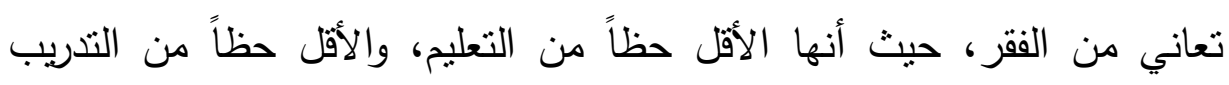

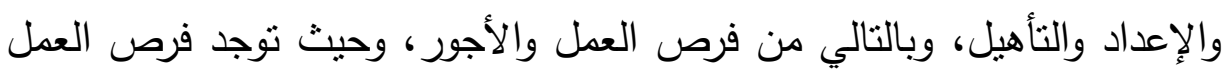

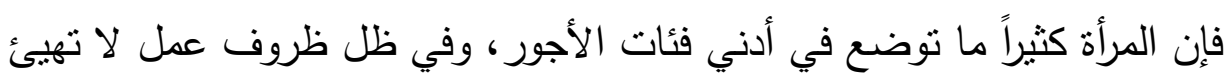

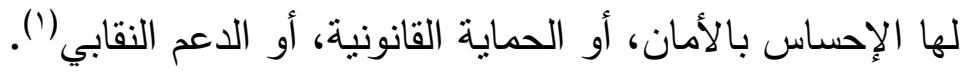

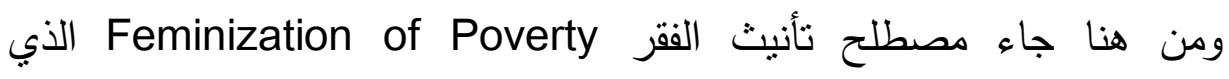
استخدمته لأول مرة - ديانا بيرث "Diana Pierce" في إنشارة على أن الأسرة

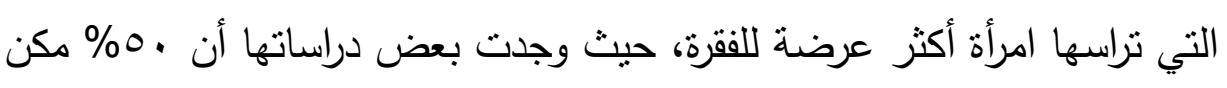
الأسر الفقيرة ترأسها امرأة، كما وصلت دراسات أخرى إلى النتيجة نفسها باستخدام مؤشرات عديدة للرفاهية(؟).

وتتعدد الأنشطة التي تتوجه إلى مساعدة الفقراء من الذكور والإناث، فنتشمل

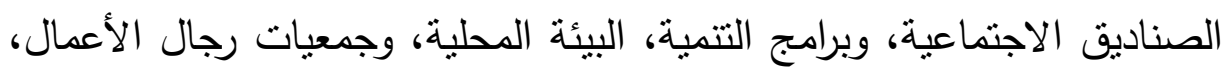

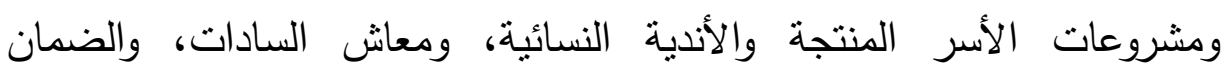
الاجتماعي، ووحدات النهوض بالمرأة في الوزارات المختلفة ومشكلة هذه الخدمة هي محدودية الوعي بها، وقدر الفئات المستهدفة لا سيما المرأة المعيلة الفقيرة 
على الاستفادة منها، وأهمية تنبى اليات تساعد على توسيع قاعدة المستهدفين من

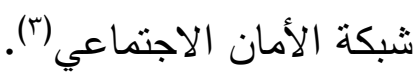

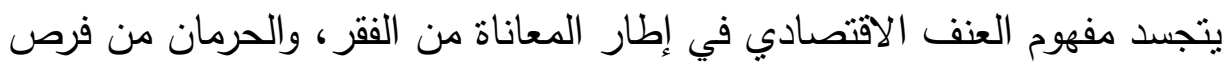

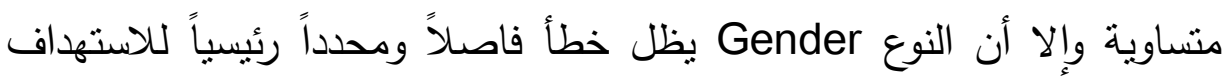
للفقر، ومعياراً لما هو متحقق من إنجازات في مجال حقوق الإنسان، تحسين مستوي العدالة الاجتماعية.

يشتمل تقرير التتمية البشرية على مفهوم للفقر ينتاوله من ناحيتين: فقرة القدرة: أب تدني مستويات قدرات الإنسان إلى الحد الذي يمنعه من المشاركة لفئه في عملية التنمية وجني ثمارها.

فقر الدخل: أي عدم كفاية الموارد لتأمين حد أدني يوفر مستوي لائقاً إنسانياً. الفقر ينطوي على مضمون اقتصادية، اجتماعي سياسي شامل الكل مما يعني الحاجة والعوز وغياب بالمشاركة وانعدام الكرامة المساواة الحقيقية(4).

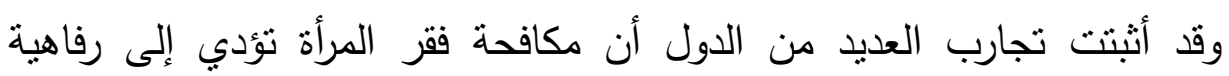
المجتمع ككل ليس فقط لأن المرأة تشكل نصف المجتمع، ولأنه قد ثبت أن الزيادة

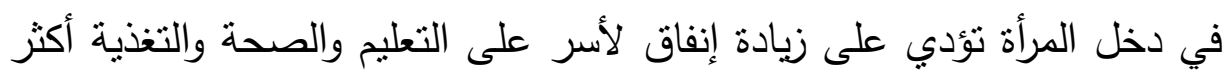

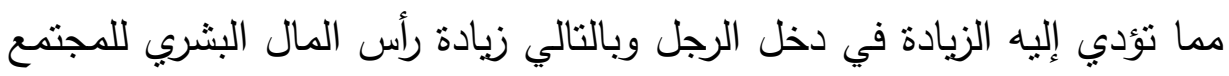

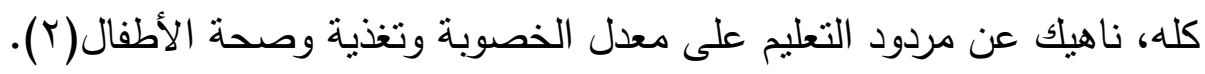




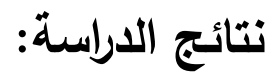

ا-تتمتع محافظة البحيرة بالعديد من المزايا التي تمثل في توافر الموارد الطبيعية والخبرات البثرية المدربة في مجالات مختلفة.

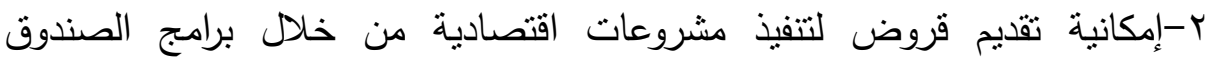

$$
\text { الاجتماعي والأسر المنتجة وغيرها من الجهات الممولة. }
$$

r-نوفر إمكانية لدى فرع المجلس القومي للمرأة بالبحيرة لتنظيم الدورات التدريبية

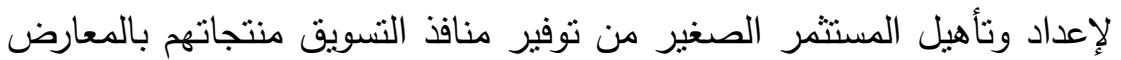
سواء بالمجان مقابل رسوم بسيطة.

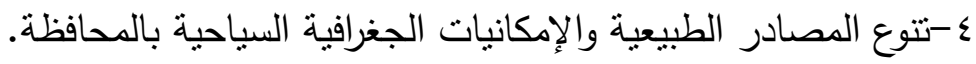
ه-توافر المواد الخام المنتجة محلياً واللازمة للصناعات الغذائية والمنزلية. צ-توافر مراكز التسويق والبيع.

V-تعدد مجالات الاستثمار المتتوع بالمحافظة مثل الزراعة والصيد والسياحة بمختلف

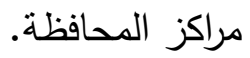

^-وضع خطة لمشروعات التصنيع الزراعي والغذائي وفقاً للمزايا النسبية والخبرات البشرية لكل مركز من مراكز المحافظة:

التعاون بين المحافظة والصندوق الاجتماعي للتتمية مع فرع المجلس القومي للمرأة بالبحيرة.

إقامة دورات للتدريب العملي لراغبي تتفيذ مشروعات التصنيع من خلال كلية الزراعة. إقامة صناعات وسيطة على مستوى أكبر على أن تكون الصناعات الصغيرة بنلك تلك

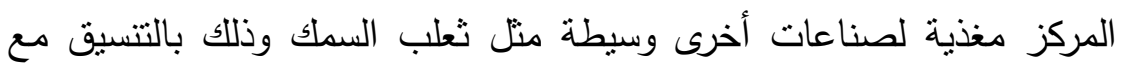

$$
\text { جمعية رجال الأعمال. }
$$

9-إقامة مشروع معالجة وتصنيع المخلفات الزراعية للاستفادة بها كأعلاف. • 1-إعطاء اهتمام خاص للصناعات الحرفية التي يمكن نسويق منتجاتها للزائرين والسائحين بمركز رشيد ووأدي النطرون. 11

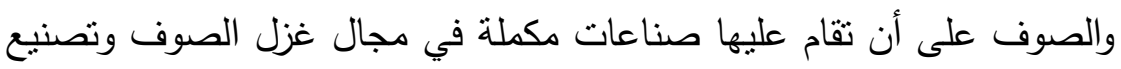


البطاطين، ويمكن تتفيذ ذلك من خلال تعاون كلية الزراعة ومديرية الزراعة

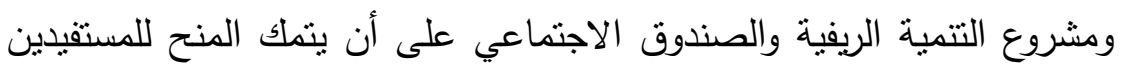
في صورة عينية وتحت إنثراف مشروع التتمية الريفية. r ب-زيادة أعداد مراكز الإعداد المهني كوسيلة لاكتساب المهارات العلمية للمرأة. rا-وضع خطة سنوية موحدة من خلال مختلف الجهات التي تقوم بتمويل وتقديم خدمات للمشروعات الصغيرة الخاصة بالمراءة مع نقديم الخدمات التدريبية

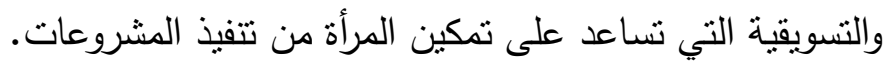

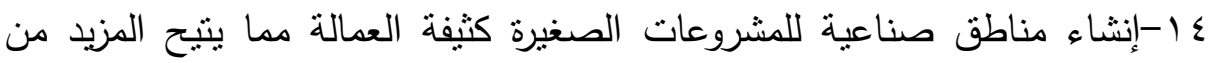

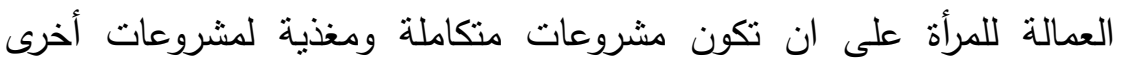
متوسطة. 10-التأكيد على التكامل بين الشربوعات الإنتاجية والمشروعات النسويقية على ان ينفذ ذلك من خلال الجمعيات الأهلية. 17

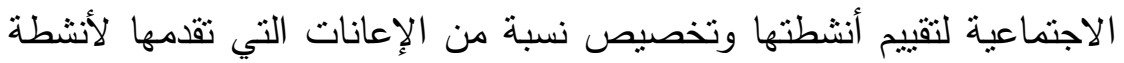

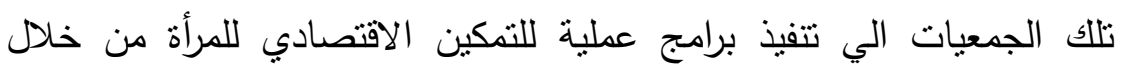
الأندية النسائية.

ا-تفعيل دور مراكز الثباب بوضع خطة زمنية لإتاحة الإمكانبات التدرييية للمرأة على تتفيذ المشروعات الصغيرة بجانب نشاط تلك المراكز .

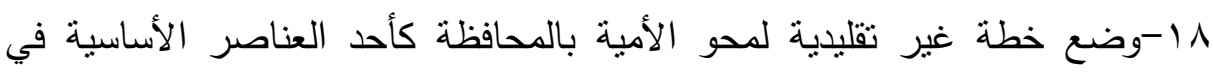
تتمية قدرات المرأة وذللك بالتتسيق مع فرع المجلس القومي للمرأة.

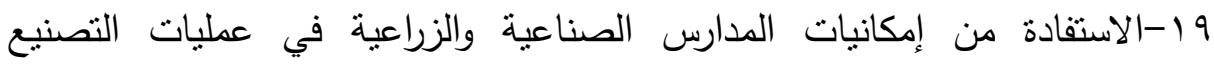
والتثريب منل صناعة الأثاث والصناعات الغذائية وفتح منافذ لها. • ץ-العودة بالمشروعات الإنتاجية بالوحدات المحلية القروية مثل المناحل وتربية ولثاتية الدواجن والنجارة والكليم وغيرها من المشروعات المختلفة. بالفيه

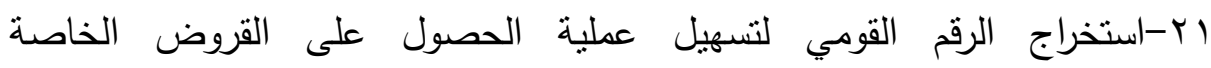
بالمشروعات الصغيرة. 


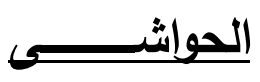

(1) محمد الفاتح عبد الوهاب العتيبي: التمكين الاقتصادي للمر آة المعيلة من خلال المشروعات الصغيرة والمتوسطة، ورقة مؤتمر (منتدى المرآة العاملة).

http://www.ahewar.org/debat/show.art.asp?aid=218347

أحمد زايد وآخرون: المرأة وقضايا المجتمع، مطبوعات مركز البحوث والدراسات

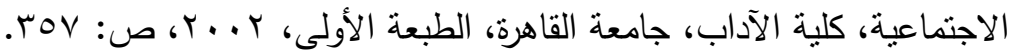

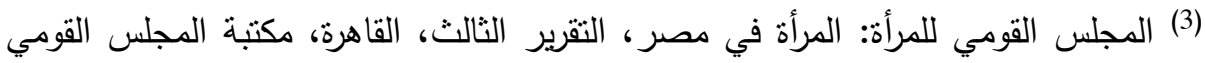

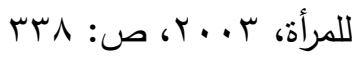

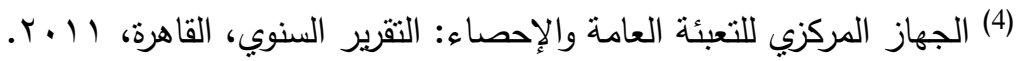
(5) نادية حليم، آخرون: المرأة المصرية والعدالة الاجتماعية والاقتصادية، القاهرة، دار الثقافة، الإهاء

$11: 0$ : 1998 (1) على عبد الرازق جلبي، محمد احمد بيومي، نادية عمر: مناهج البحث الاجتماعي، دار

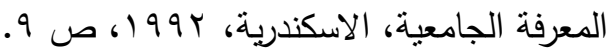

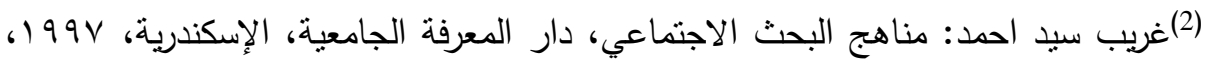
ص (3) على عبد الرازق جلبي: تصميم البحث الاجتماعي الأسس والاستراتيجيات، دار المعرفة

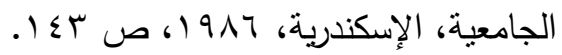

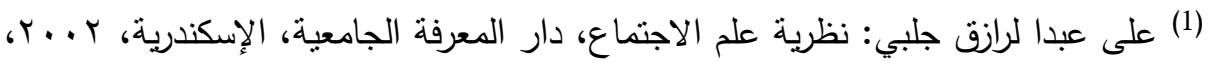
. $\leqslant \leqslant$ (2) عبد المنعم يوسف السنهورى: نظريات واتجاهات معاصرة، خدمة الفرد الإكلينيكية، المكتب

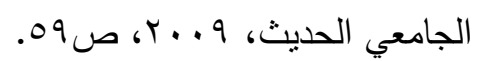
(3) ابراهيم عبد الهادي المليجي: نتظيم المجتمع مداخل نظرية ورؤية واقعية، دار المعرفة

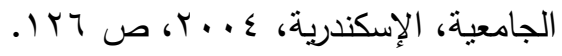
(1) سلوى عثمان الصديقي، جلال الدين عبد الخالق: نظريات علمية واتجاهات معاصرة في

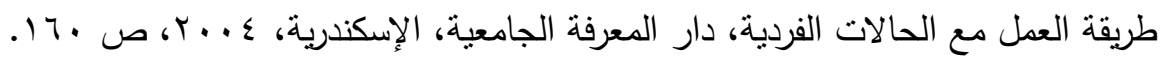


(2) السيد على شتا: نظرية علم الاجتماع، دار المعرفة الجامعية، الإسكندرية، ب99 (1، ص

(3) وكالة الأهرام للتوزيع، المرأة العربية، مكتبة الأهرام للبحث العلمي، V... Y، ص ا: ص

(4) شهيدة الباز وآخرون: المرأة في المنظمات الأهلية في مصر، ورقة عمل مقدمه للجنة

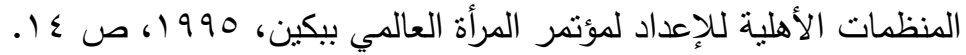

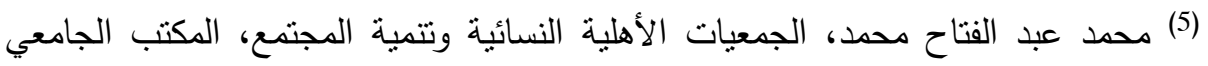

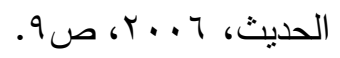

(1) السيد رمضان: مدخل في رعاية الأسرة والطفولة (النظرية والتطبيق)، الإسكندرية، المكتب

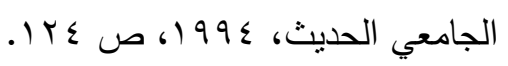

(2) Swisher Harim: I.edsing le parents families at issue, green hahven press some gig at VSA. California , 1997, P80.

(3) سناء الخولى: الزواج والعلاقات الأسرية، دار المعرفة الجامعية، الإسكندرية، ، 99 (1، ص

(4) هدى محمد قناوي: "سيكولوجية المسنين" مركز التتمية البشرية والمعلومات الطبعة الأولى،

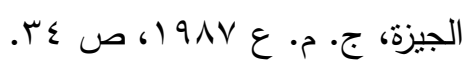

(5) Atchely G.R: the sociology to Preferment John Wiley and sons Inc. New York, 1970, P59.

(6) نجوى أحمد حسين دره: المتطلبات التربوية لمواجهة الأم لبعض المشكلات الناتجة عن

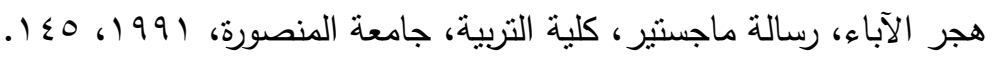

(1) هبه أحمد عبد اللطيف: تفعيل دور المنظمات غير الحكومية لتمكين المرأة المعيلة، رسالة

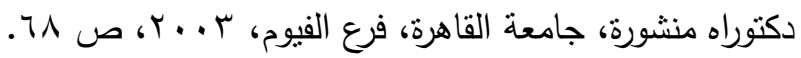

(2) محمد محمود مصطفى: "الخدمة الاجتماعية وأزمة الإفراج عن السجين"، مجلة القاهرة

للخدمة الاجتماعية، الجزء الثاني، العدد الخامس، يناير، ؛ 99 (، ص لـ 007.

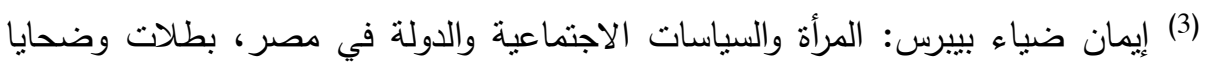

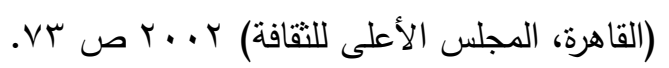

Doi: $10.12816 / 0041728$ 
(4) سهير فؤاد أنور : محددات فعالية وكفاءة وإنتاجية النساء في بعض محافظات الجمهورية -

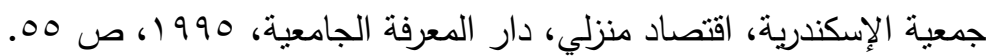

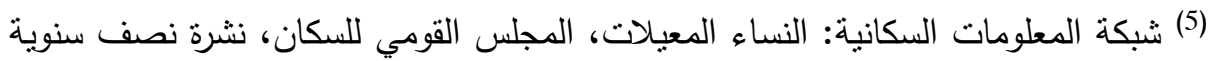

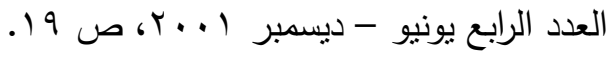

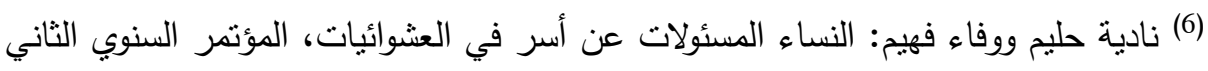

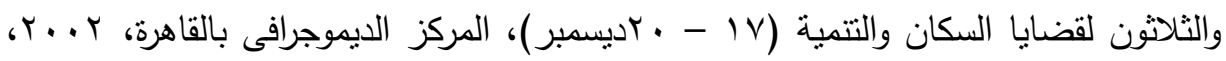

(1) ميشيل صبحي: مشروع الدعم الفني والمؤسسي للمنظمات غير الحكومية لتنفيذ وثيقة بكين

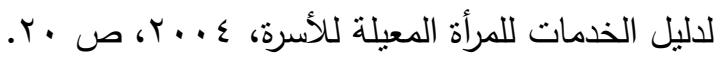

(2) وصفى نور الدين: ورقة عمل حول المرأة والأمية في العشوائيات ومؤتمر الاستراتيجية كانية

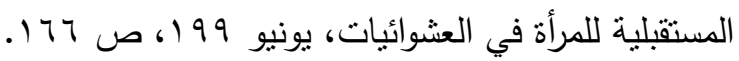

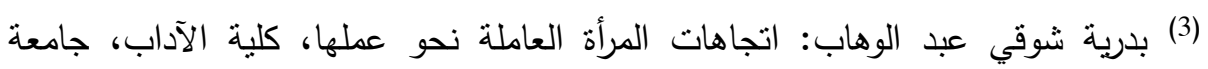

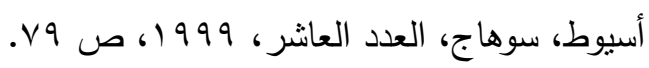

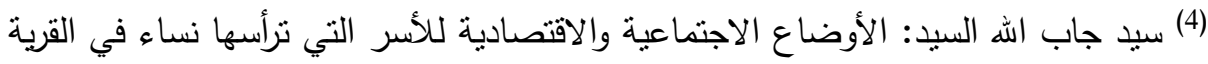

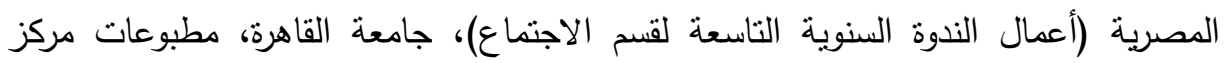

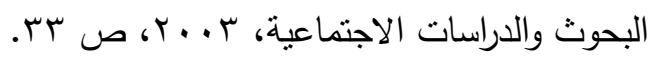

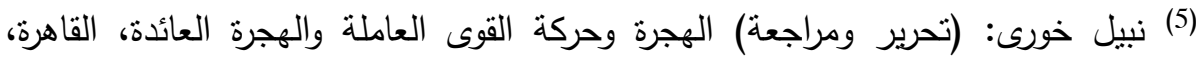

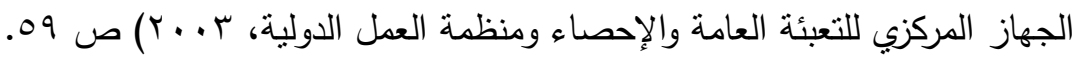

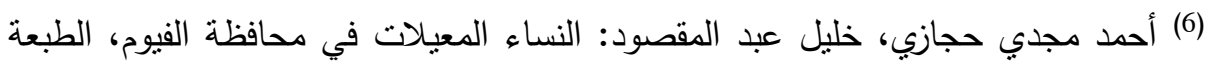

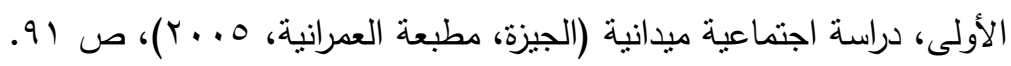

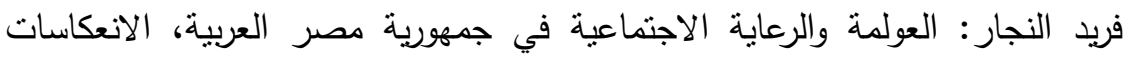
الاقتصادية والاجتماعية، ورقة عمل، المؤتمر السنوي الحادي عشر لكلية الخدمة الاجتماعية

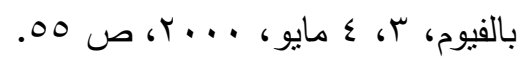
(2) United Nation: female headed house holds in selected conflict stricken ESCW A Areas, economic and social commission for western ASIA 2000. 
(3) هدى بدران: نساء مسئولات عن أسر (القاهرة، المجلس الدولي للسكان، المجلس الدولي

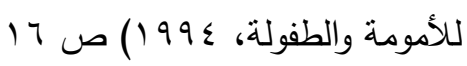

(4) رسالة البونسكو: النساء نصف العالم، المؤتمر الرابع للمرأة ببكين (القاهرة، مركز

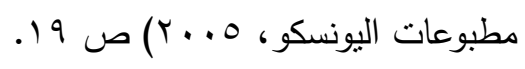
(5) إقبال الأمير السمالوطى وآخرون: النساء المعيلات لأسر (القاهرة، مجلة العالى للخدمة

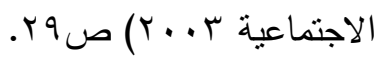

(6) عبد الخالق محمد عفيفى، نعيم عبدالوهاب شلبى: مشكلات المرأة المعيلة فى المجتمع

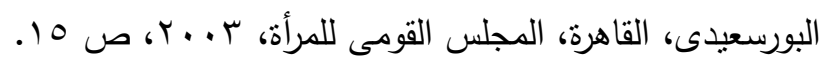

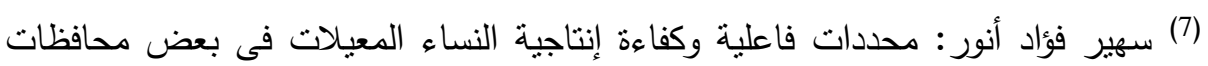

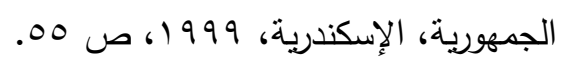

(8) A statistical portrait: women and men in Egypt, economic social commission for western Asia , 2003, P.19.

(9) جمهورية مصر العربية، المجلس القومى للمرأة، البنك الدولى، مصر والنوع الاجتماعى، -

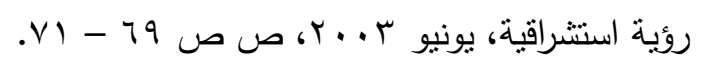

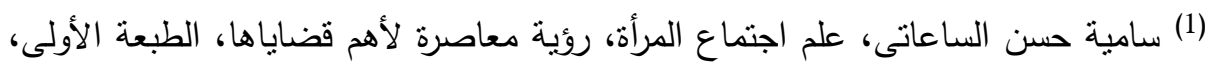

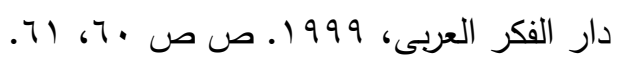
(2) Van Neman Reeve: the cauces of pouretgin , in female headed holds: the case greu, University of movghand - college - park, 1998 , p.90.

(3) شريف حتاته: المرأة وتقسيم العمل الدولى "حول فكر سمير أمين" فى عبدالباسط عبدالمعطى (تحرير) العولمة والتحولات المجتمعية فى الوطن العربى، القاهرة، مكتبة مدبولى، . r $\leqslant$ r ص 1999 (4) هدى بدران: نساء مسؤلات عن أسر ، القاهرة، المجلس القومى للأمومة والطفولة، المجلس

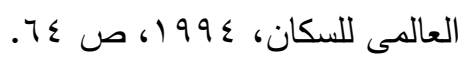
(5) بنجامين سبوك، دليل الوالدين لتشئة الأطفال من الميلاد حتى المراهقة، إضافة ومراجعة

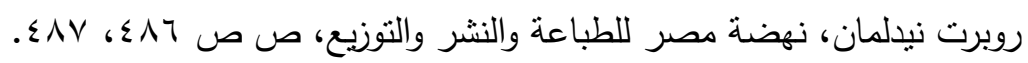


(6) البسيونى عبد اله جاد: علم الاجتماع القانونى ودراسة حقوق الإنسان، الطبعة الأولى،

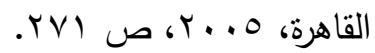

(1) مديحة الصفطى، القانون والواقع: العقبات الاجتماعية والثقافية أمام مساهمة المرأة "(بحث

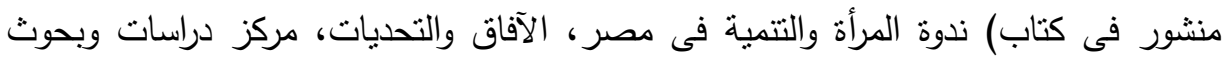

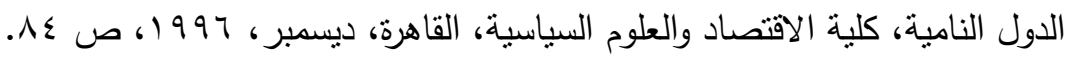

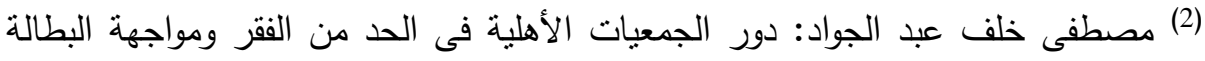

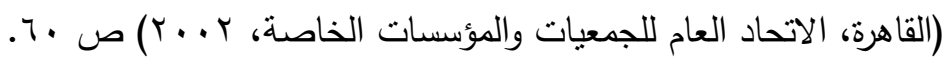

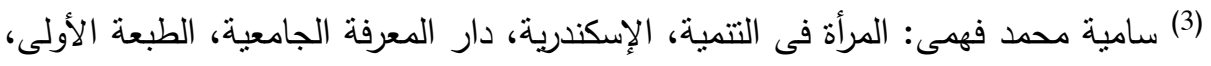

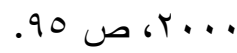

(4) perez sania M.U.Saitino children: asatus reports and shing, national councilof crao , 2000, P.10.

(1) عادل ذكى عبد السيد، أبو الحسن عبدالوهاب محمد: بحث شبكة مساندة المرأة المعيلة

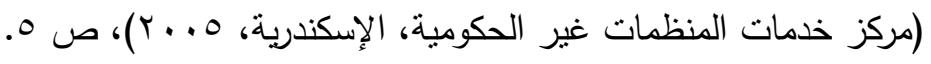

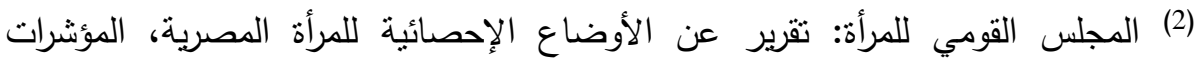

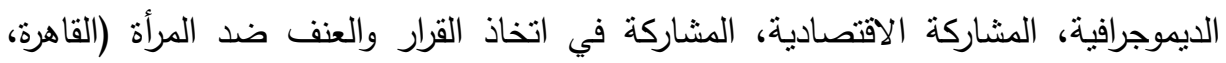

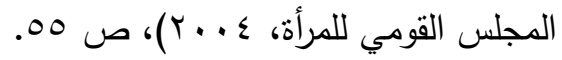

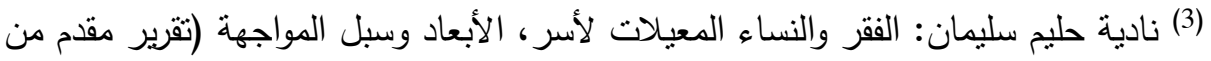

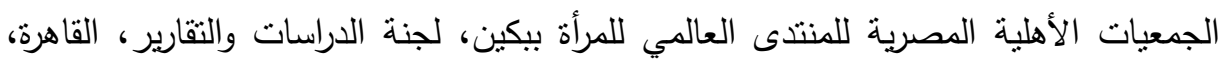
.10. 1990 (4) Geraldine Downey \& phylis Moen: "personal Efficacy, income , and family Transitions: A longitudinal study of women heading househdds), Journal of Health and Behavior, University social of Mechigan, vol I.28, 1987) P.(330).

(5) مديحة الصفطى: القانون والواقع: العقبات الاجتماعية والثقافية أمام مساهمة المرأة، بحث

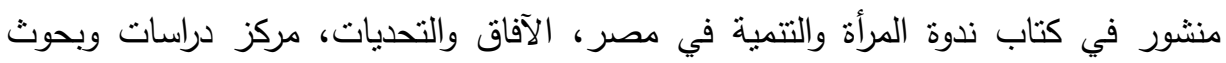

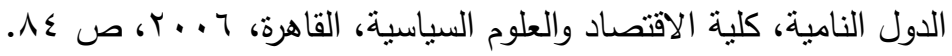


(1) حمدي عبد العظيم، أثز قيمة التعليم وعمل المرأة على نوع النشاط الاقتصادي المصري،

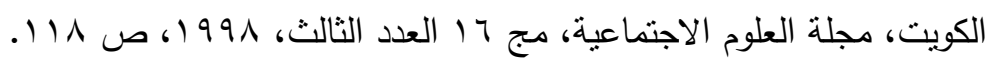

(2) إقبال الأمير السمالوطى وآخرون: النساء المعيلات لأسر المشكلات والحلول (القاهرة،

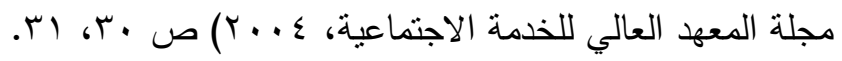

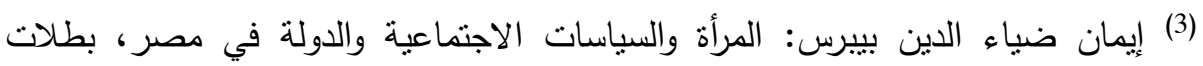

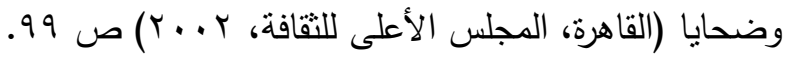

(4) Weng Winifred Fin Egan: s study of return migrant well being the difference between male and female headed Mexican house holds, PHD, university of Illinois of Urban a champignon , 1998, P.117.

(') نجوى الفوال، المرأة المصرية والتحديات المجتمعة، المركز القومي للبحوث الاجتماعية

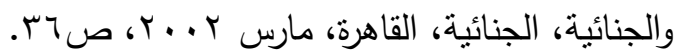

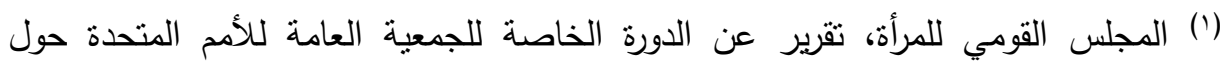

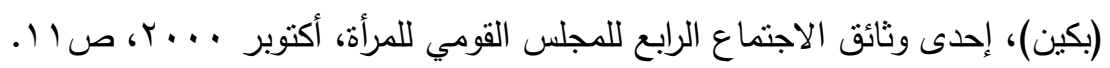

( $)$ Zinab Khadr\& Imnan Farid, Who is the head? A paper presented in seminar on - social categories in population studies, Cairo Egypt, September 15/18, 1999, sponsored by lussp cmitte an anthropological demography and the new Arab demography project of the social search center at the AUG, 1999.

(r) نجوى الفوال، المرأة المصرية والتحديات المجتمعة، المركز القومي للبحوث الاجتماعية ، منظمة الأمم المتحدة للتربية والعلوم UNFPA والجنائية، صندوق الأمم المتحدة للسكان

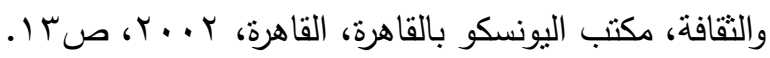

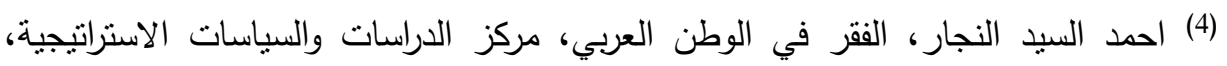

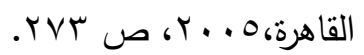

(ז) هبة الليثي: المرأة المصرية والأهداف الإغاثية ألفية، المؤتمر الرابع للمجلس القومي للمرأة،

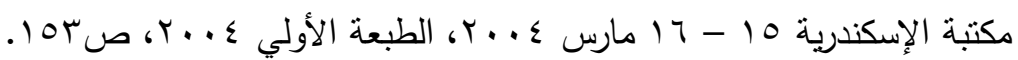

